\title{
Pairing Degree-WH Clauses in Mandarin
}

\author{
Niina Ning Zhang \\ National Chung Cheng University
}

\begin{abstract}
In Mandarin, if two-degree wh-question-like clauses are combined, the whphrases do not have a question reading. This paper argues that such a pairedwh declarative is an equative comparison construction, like the as...as equative in English, and the first clause denotes the standard of the comparison. Such declaratives, like a degree comparison construction, are derived by the occurrence of a comparison quantifier, and predicate abstraction applies to each clause. The paired wh-forms are the variables. This research shows that Mandarin does have degree quantificational comparison constructions, and it is possible for both clauses of a comparison construction to have a wh-form.
\end{abstract}

\section{Keywords}

degree, equative, predicate abstraction, paired degree-variable construction, wh

Studies in Chinese Linguistics, Volume 42, Number 2, 2021, 121-160 DOI: 10.2478/scl-2021-0004 (C) 2021 Niina Ning Zhang. Studies in Chinese Linguistics is published by Sciendo on behalf of T.T. Ng Chinese Language Research Centre, Institute of Chinese Studies, The Chinese University of Hong Kong. This work is licensed under the Creative Commons Attribution-NonCommercial-NoDerivatives 4.0 International License. 


\section{Introduction}

This paper shows how a special wh-construction in Mandarin leads us to new understandings of the grammar of comparison constructions and one type of multiple wh-clause constructions. A clause like (1a) is a wh-question. ${ }^{1}$ When two such clauses are combined directly, without any linking element, the resultant complex, such as (1b), is not a question any more. ${ }^{2}$ In such a construction, the wh-forms are duome (short form: duo 'how' or duoshao 'how much, how many', followed by a gradable expression. I call such a construction Paired degree Variable Construction (PdVC).
a. Zhiming duo gao?
Zhiming how tall
'How tall is Zhiming?'
b. Zhiming duo gao, Ajiao (jiu) duo gao. Zhiming how tall Ajiao then how tall 'Ajiao is however tall Zhiming is.'

A PdVC is different from other paired variable constructions (PVCs), such as (2a) (Cheng and Huang 1996) and (2b), systematically, and is similar to a comparison construction, such as (3), also systematically. The goal of this paper is to explain the distinctions and the similarities.
a. Zhiming
mai
shenme, Ajiao
(jiu)
mai
shenme.
Zhiming buy what Ajiao then buy what
'Ajiao buys whatever Zhiming buys.'
b. Yi ren chuang huo yi ren fuze.
one person make trouble one person responsible
'If anyone makes a trouble, that person is responsible for it.' (Chen 2015: 11)

(3) Mary is as tall as John is.

In a PdVC, the word jiu 'then' in the second clause is always allowed. In the informal speech of many speakers, it can be optional. It is a correlative adverb, seen in various bi-clausal constructions (e.g., Chao 1968: 114).

1 BI: comparative; CL: classifier; DE: modification or possession; EQ: equative quantifier; EXCL: exclamative; EXP: experiential; PM: parameter marker; PRF: perfective; Q: question; SM: standard marker.

2 A declarative clause can be embedded in a question or exclamative context. The same is true of a PdVC:

$\begin{array}{lllllllll}\text { (i) } \mathrm{Ni} & \text { shi-bu-shi } & \text { juede } & { }^{\mathrm{PdV}} \mathrm{Lili} & \text { duo } & \text { gao } & \text { Mimi } & \text { jiu } & \text { duo gao } \\ \text { You be-not-be } & \text { think } & \text { Lili } & \text { how } & \text { tall } & \text { Mimi } & \text { then } & \text { how tall }\end{array}$ 'Do you think Mimi is however tall Lili is?'

(ii) Yuanlai $\left[{ }^{\text {PdVC }}\right.$ Lili duo gao Mimi jiu duo gao] a! Tai bukesiyi le! Oh Lili how tall Mimi then how tall EXCL too.much incredible PRT 'Oh, Mimi is however tall Lili is! What a surprise!' 
It occurs in the matrix clause of the conditional ruguo 'if', the factive jiran 'since', and the temporal $y i$ 'once' constructions. Zhang (2020) argues that this use of jiu is semantically vacuous. I do not discuss the word in this paper.

There is also a pragmatic issue that we put aside: the speaker of a PdVC shows her ignorance or indifference toward the detail content expressed by the left clause of the construction. In our translations, we often use a wh-ever word to encode the effect. The effect is also seen in free relatives (Luo and Crain 2011: 774). This effect can be taken care of by some anti-focus feature in the C-domain.

Words such as same and different are used to compare various kinds of elements. We explore how a comparison meaning is expressed by a construction without any comparison marker, including the word that means 'same'. We argue that a PdVC is an equative comparison construction, like the one in (3). Like (3), it is degrees that are compared in a PdVC.

The major differences between PdVCs and other kinds of PVCs such as those in (2) are reported in $\S 2$. Then in $\S 3$ is shown why the available analyses of whPVCs are not applicable to PdVCs. In $\S 4$ is argued the quantificational comparison structure of PdVCs. In $\S 5$, a general syntactic structure of PdVCs is given, while $\S 6$ concludes.

\section{Paired degree-variable constructions versus other paired- variable constructions}

Four major properties of PdVCs distinguish them from other kinds of PVCs in Mandarin.

2.1 The variable form must be a wh-form

In a PdVC, a gradable expression is preceded by a wh-form, such as duo(me) 'how much (stative)' and duoshao 'how many or how much (N)' in both clauses. In (4a) and (4b), the gradable expressions are preceded by a non-wh form, and in (4c), the two instances of the bare gradable gao 'tall' are paired. None of the examples is acceptable.

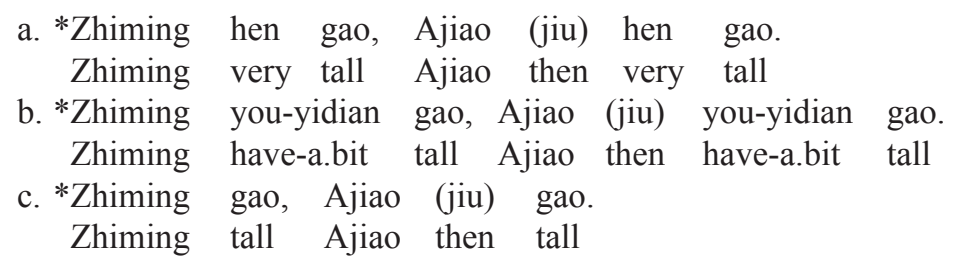

If the lexical part of the pair in a PVC is not gradable, the variables may take a wh-form, as in (2a), or a non-wh form, as in (2b). More non-wh-PVC examples are in (5) (the examples are from an anonymous reviewer of another paper). 
(5) a. Lai yi ge, wo sha yi ge. come one $\mathrm{CL}$ I kill one $\mathrm{CL}$ 'I will kill every person that comes.'

b. Yi ren zuo shi, yi ren dang. one person do thing one person responsible 'If a person does something (disastrous), the person takes the responsibility.'

c. Ren bu fan wo, wo bu fan ren. people not offend me, I not offend people 'As long as people do not offend me, I do not offend them.'

d. Ziji de wenti, ziji jiejue. self DE problem self solve

'If it is one's own problem, one should solve it himself.'

An implication of this property of PdVCs is that there must be a wh-dependency exclusively in the constructions. Later, the comparison analysis covers this property.

2.2 No conditional complementizer is allowed

Complementizers such as ruguo 'if', yaoshi 'if', zhiyao 'only if', zhiyou 'only if', and wulun 'no matter' are all rejected in a wh-PdVC, as seen in (6), although they may occur in other wh-PVCs, as seen in (7), and non-wh PVCs, as seen in (8) ([6b] and [8c] are from two reviewers).

a. *[\{Ruguo/yaoshi/zhiyao/zhiyou/wulun $\}$ if/if/only if/only if/regardless

Zhiming duo gao, Ajiao (jiu) duo gao].

Ajiao then how tall

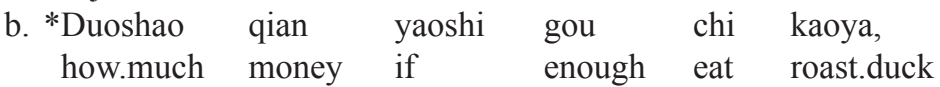

ni jiu gei wo duoshao qian.

you then give me how.much money (cf. Lin 1996)

(7) a. Shei yaoshi qudao ta nüer, shei jiu keyi who if marry his daughter who then may jicheng ta de shiye. inherit he DE enterprise

'Whoever marries his daughter, he may inherit his enterprise.' (Lin 1996: 168)

b. Zhiyao wo shuo shenme, nimen liang wei jiu daying as.long.as I say what you two CL then promise shenme, na jiu gan'enbujin. what that then in.your.debt 'You two promise me whatever I say. Then, I am forever in your debt.' (Yang 2019: 14) 

$\begin{array}{llllll}\text { c. Zhiyou shenme pianyi, Xiao-Wang cai mai-le } & \text { shenme. } \\ \text { only.if } & \text { what } & \text { cheap Little-Wang then buy-PRF } & \text { what }\end{array}$ 'She only bought whatever was cheap.'

(Wang 2016: 69)

d. Wulun yujian shenme, jiu shuo shenme. no.matter encounter what then say what 'See something, say something.'

(Yang 2019: 22)

(8)

a. $\underline{\text { Ruguo }}$ lai yi ge, wo jiu sha yi ge. if come one CL I then kill one CL 'If one person comes, I will kill that person.'

b. Ruguo shi ziji de wenti, jiu ziji jiejue. if be self $\mathrm{DE}$ problem then self solve

'If it is one's own problem, one should solve it himself.'

c. (uguo) zhe.bian gao yidian, na.bian jiu hui duan yidian. if this.side tall a.bit, that.side then will short a.bit

'If this side is taller to a degree, that side will be shorter to the same degree.'

An implication of this property of PdVCs is that the two wh-forms establish a certain dependency that is not compatible with a conditional one. None of these complementizers can introduce the standard clause of a comparison construction. The comparison analysis, to be presented, predicts the unacceptability of (6).

\subsection{Allow different wh-forms}

The two wh-forms of a PdVC can be different: one can be duome 'how' and the other can be duoshao 'how much, how many', as seen in (9a). However, in other kinds of wh-PVCs, the two wh-forms must be identical, as seen in (9b). ${ }^{3}$

a. Xiangzi duome da, jiu zhuang duoshao shu. box how big then put.in how.many book 'Put as many books in the box as its capacity allows.'

b. $\mathrm{Ni}$ xihuan shei wo (jiu) piping $\{$ shei $/ *$ shenme-ren $\}$. you like who I then criticize who/what-person 'I criticize whoever you like.'

(Cheng and Huang 1996: 129)

3 I am grateful to a reviewer who points out that although the whole forms of the two wh-elements can be different, the first morpheme of the wh-forms must be the same in a PdVC. In (9a), both clauses have duo- 'how'. In (i), duoshao cannot be paired with ji-ben. Although the possible variation of the whole wh-forms still challenges several approaches (see [26]), I leave this more refined parallelism of the two clauses of a PdVC for future research.

(i) Zhangshan mai-le duoshao shu, Lisi jiu mai-le \{duoshao/*ji-ben $\}$ shu.

Zhangsan buy-PRF how.many book Lisi then buy-PRF how.many/how.many-CL book

'Lisi bought the same quantity of books as Zhangsan did.'

Note that in various types of wh-PVCs, the post-wh forms can be different (Hua 2000). See (24). 
Non-wh PVCs also reject different forms of the variables (the examples are from an anonymous reviewer of another paper):

$\begin{array}{cllllll}\text { a. * }{ }^{\text {Lai }} & \text { yi } & \text { ge, wo } & \text { sha } & \text { yi } & \text { ren. } \\ \text { come } & \text { one } & \text { CL I } & \text { kill } & \text { one } & \text { person } \\ \text { b. * Lai } & \text { yi } & \text { ren, } & \text { wo } & \text { sha yi } & \text { ge. } \\ \text { come } & \text { one } & \text { person } & \text { I } & \text { kill } & \text { one } & \text { CL }\end{array}$

This property of PdVCs means that only the identity of the degrees of the two parts of a variable pair is relevant in the constructions. This is not the case for other PVCs, where the identity of the variable forms of a variable pair is required.

2.4 Disallow more than one pair of variable

A PdVC must have two clauses, and in each clause, there is only one variable allowed. Examples like those in (11) indicate that a non-PdVC allows multiple pairs of variables. In contrast, compared with the acceptable single clause in (12a), which is not a PdVC, (12b) and (12c) each have multiple pairs of wh-variables across the two clauses, and the PdVCs are not acceptable.

(11) a. Ruguo shei na-le shenme, shenme jiu shi shei de. if who take-PRF what what then is who DE

'If one takes anything, that thing belongs to the person.'

(Chen 2015: 11)

b. Ta chi sha yong sha, wo jiu chi sha yong sha. he eat what use what I then eat what use what 'Whatever he eats I eat and whatever he uses I use.' (Li 2019: 143; cf. Cheng and Huang 1996: 157 [75])

c. Ren bu fan wo, wo bu fan ren/??ta(men). people not offend me, I not offend people/he/them 'As long as people do not offend me, I do not offend them.'

d. (Ruguo) ta xiang rang duoshao ren jiao duoshao shui, if he want ask how.many people pay how.much tax, jiu keyi rang duoshao ren jiao duoshao shui. then can ask how.many people pay how.much tax 'If he wants a large number of people to pay a large amount of tax, he can ask them to do so.'

(from a reviewer)

(12) a. Duo da de panzi (jiu) you duo da de laobing. Single clause how big DE plate then have how big DE pancake 'The size of a plate correlates with the size of a pancake.'

b. *Duo da de panzi you duoshao shala, how big DE plate have how.much salad duo da de wan (jiu) you duoshao xiancai. how big DE bowl then have how.much pickle 


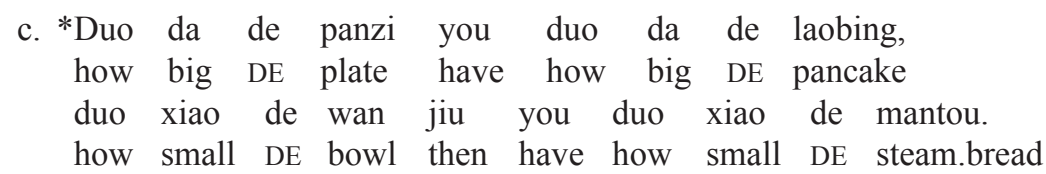

An implication of this property of PdVCs is that only one dependency between the two parts of a pair is allowed in a PdVC. This is the same constraint seen in a comparison construction, where a comparison is established between two items only. The restriction suggests that a PdVC can be a comparison construction, whereas other PVCs are not. ${ }^{4}$

A PdVC is distinguished from other PVCs in all of the above aspects. On the other hand, a manner wh-PVC also rejects ruguo, as seen in (13a) (Lin 1998: 248: zenme rejects ruguo), but it disallows different wh-forms (cf. 2.3), as seen in (13b), and allows multiple pairs (cf. 2.4), as seen in (13c). Therefore, a manner wh-PVC is still different from a PdVC.

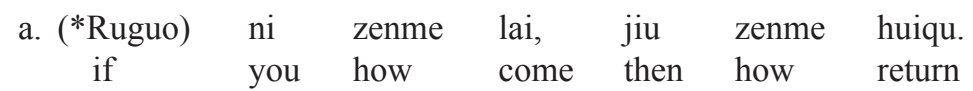

b. ${ }^{*} \mathrm{Ni}$ zenme lai, jiu ruhe huiqu. you how come then how return

c. Ni zenme qu nali, wo jiu zenme qu nali. you how go where I then how go where 'I will go wherever you go and in however the way you do.'

In this section, I have presented four distinctive properties of PdVCs from other PVCs. They all suggest that the former can be a comparison construction, whereas the latter cannot. The former thus needs an analysis different from those that have been proposed for the latter. In $\S 3$, we see why these analyses are not applicable to PdVCs.

\section{The roads not taken}

\subsection{Seven analyses}

Two or more of the following analyses of wh-PVCs are proposed as a combined analysis for some scholars. But none of the analyses has to lead to another analysis. In order to reveal the restrictions of each analysis, I discuss them separately.

4 As pointed out by a reviewer, although multiple pairs of degree wh-expressions are not allowed, a pair of degree wh-expressions can co-occur with another pair of individual wh-expressions. An analysis of a construction like (i) will have to wait for future work, after both a PdVC and a nondegree PVC have been analyzed.

(i) Shei da-le duoshao fan, shei jiu chi-le duoshao fan. who do-PRF how.much food who then eat-PRF how.much food 'For every person $\mathrm{x}$ and every degree $\mathrm{d}$, if $\mathrm{x}$ bought $\mathrm{d}$-much food, $\mathrm{x}$ ate d-much food.' 


\section{A. The conditional analysis}

A wh-PVC has been assumed to be a type of conditional (Cheng and Huang 1996; Huang 2018, among others). Indeed, for a non-PdVC, it can usually be paraphrased as a conditional construction, and adding ruguo 'if' to the first clause does not change the meaning of the construction, as seen in 2.2. But our 2.2 shows that a PdVC rejects ruguo, and it cannot be interpreted as a conditional. (1b) does not mean that Ajiao's height, which is a stable property, varies, depending on Zhiming's height.

Moreover, according to Pan and Jiang (2015) and Cheng and Huang (2020: 173), the variables in a conditional construction do not have to be a wh-form. One of their examples is (14):

(14) Shang-ci shei mei jiang-wan, jintian jiu you $\{$ shei/ta $\}$ xian kaishi. last-time who not talk-finish today then with who/3SG first begin 'Today let's begin with whoever did not finish his talk last time.'

(Lin 1996: 217)

But our 2.1 shows that each of the two clauses of a PdVC must have a wh-form. This is another difference between PdVCs and conditionals.

B. The Across-the-Board (ATB) movement analysis

Huang (2018) brings us to speculate whether wh-PVCs can be derived by a covert ATB movement of the two wh-forms (he further assumes that wh-PVCs are derived by unselective binding; we discuss this binding in Part $\mathrm{C}$ below). If a movement starts from two or more launching sites but lands in a single site, it is called ATB movement (e.g., Who did Jim like_and Kim hate _?). However, first, the two wh-forms of a PdVC can be different, as seen in (9): one can be duome and the other can be duoshao. No ATB movement allows different elements to move to the same site.

Second, an ATB movement is used only for symmetrical coordinate structures (Wilder 1994: 292, 295). PdVCs do not satisfy the condition. No coordinator is allowed between the two clauses of a PdVC. Also, unlike in a symmetrical coordinate construction, changing the order of the two clauses of a PdVC will change the meaning of the construction (see a similar observation on wh-PVCs in Luo and Crain 2011: 773 fn. 9). The two examples in (15) are not judged semantically identical. (15a) asserts that Ajiao's height is not less than Zhiming's height, but (15b) asserts that Zhiming's height is not less than Ajiao's height. ${ }^{5}$

5 The assertion asymmetry is reflected in Luo and Crain's (2000: 772) claim that in a wh-PVC, the first wh-form is a topic and the comment is included in the second clause. But a topic-comment structure does not need wh-forms. 
(15)
a. Zhiming duo gao Ajiao jiu duo gao. Zhiming how tall Ajiao then how tall 'Ajiao is however tall Zhiming is.'
b. Ajiao duo gao Zhiming jiu duo gao. Ajiao how tall Zhiming then how tall 'Zhiming is however tall Ajiao is.'

Third, the assertion asymmetry of PdVCs is also seen in another fact: a PdVC cannot answer a question that is targeted to the left-clause (cf. Liu 2018: 127 on wh-PVCs). The PdVC in (16c) is able to answer the question in (16b), but not (16a). Also, a PdVC cannot answer two questions at the same time, as shown in (17). In my proposed comparison analysis of PdVCs, the left clause is the standard of the comparison, and thus only the right clause is asserted. The asymmetry is found in all comparison constructions, e.g., Jane is as tall as Bill can answer the question How tall is Jane?, but not How tall is Bill?, or How tall are Bill and Jane, respectively?
a. Zhiming duo gao? Zhiming how tall 'How tall is Zhiming?'
b. Ajiao duo gao? Ajiao how tall 'How tall is Ajiao?'
c. Zhiming duo gao, Ajiao jiu duo gao. Zhiming how tall Ajiao jiu how tall 'Ajiao is however tall Zhiming is.'
a. Qing gaosu wo Zhiming he Ajiao de shengao. please tell I Zhiming and Ajiao DE height 'Please tell me Zhiming's and Ajiao's height.'
b. Ans.: \#Zhiming duo gao, Ajiao jiu duo gao. Zhiming how tall Ajiao jiu how tall 'Ajiao is however tall Zhiming is.'

Thus, PdVCs do not satisfy the symmetrical coordination condition for an ATB movement. Also, covert ATB movement at LF has been claimed not possible in Bošković and Franks 2000. If a PdVC were derived by a covert ATB movement, more should have been said.

\section{Unselective binding without an ATB movement}

Can the dependency in a PdVC be an unselective binding without an ATB movement? In an unselective binding, one (null) quantifier binds multiple variables (Cheng and Huang 1996; Huang 2018; Chierchia 2000). Binding rules are restricted to nominals. Chierchia (2000) further claims that the variables in wh-PVCs are indefinite pronouns, similar to the Italian subject clitic si and the English one. But the variables of a PdVC are not nominals, and thus the binding rules do not apply. Later in this paper, I will propose an analysis similar to unselective binding in the aspect that one null quantifier is linked to two variables. 
It needs to be pointed out that the current implementation of unselective binding is not sufficient to explain the properties of PdVCs, even if it is extended to non-nominal dependencies. First, the unselective binding pattern itself does not restrict the number of the variables. The number of variables can be more than two in a non-PdVC, but must be two in a PdVC (2.4). Second, the unselective binding pattern itself does not restrict the form of the variables. It is thus not sufficient to explain why the variables in a PdVC must be wh-forms, rather than other possible forms of variables, compared with other kinds of PVCs (see [2b] and [5] in 2.1). Third, the current unselective binding analysis is too restrictive to cover the fact that the two variables in a PdVC can be of different forms (2.3). According to Cheng and Huang (1996: 139), in the clauses A and B of a wh-PVC, "for every variable in A, there must be an identical variable in B".

\section{The movement copy analysis}

To explain the multiple occurrences of wh-forms in a wh-PVC, Bruening and Tran (2006) claim that the two wh-forms realize two copies of a movement chain from one clause to the other. Since the two wh-forms can both surface at thetapositions, the movement is not an operator movement. Non-identical wh-forms in a PdVC (2.3) challenge this analysis directly.

Chen (2019) also claims that the two wh-forms of a wh-PVC are two copies of a movement chain. In addition to the possible different forms of the variables in a PdVC, her analysis also has another problem. She assumes that there are two obligatory A-bar movements to derive a wh-PVC. Step 1: the whform moves to the left edge of the containing clause, to achieve (a correlative type of) relativization (We discuss the correlative issue in part E below). The lower copy of this movement is assumed to be PF-visible. Step 2: the clause that contains the wh-form moves to left-edge of the matrix clause. A simplified version of her analysis of (18a) is (18b) (Chen 2019: 10). In (18b), what moves to the left of the clause [you like what], and then this clause moves to left edge of the whole construction.
a. $\mathrm{Ni}$ xihuan You like shenme, wo jiu
zhu cook shenme. 'I cook whatever you like.'
b. $\left[_{I P} \text { [you like what }\right]_{k}\left[{ }_{I P}\right.$ I cook $\left[_{D P} \mathrm{D}\left[\right.\right.$ what $\left.\left.\left.\left._{\mathrm{j}}[\text { you like what }]_{\mathrm{k}}\right]\right]\right]\right]$

The assumed obligatory movement of Step 2 is not well motivated. It is claimed that the movement of the clause is necessary in order to avoid "two copies of wh-phrases to be too close together" (Chen 2019: 12). However, two identical whforms may occur even in a row in the language, as seen in (19) (also see [11a]). Thus, we see the flaws in this movement analysis of wh-PVCs.
a. Ta shei shei dou renshi.
he who who all know 'He knows everyone.' 
$\begin{array}{llllll}\text { b. Wo shi duome } & \text { duome } & \text { de } & \text { gaoxing } & \text { a! } \\ \text { I be how } & \text { how } & \text { DE } & \text { glad } & \text { EXCL } \\ \text { 'How happy I am!' } & & & & \end{array}$

\section{E. The correlative or free relative analysis}

Luo and Crain (2011) (also Huang 2010) claim that a wh-PVC is a free relative clause construction or correlative construction that is seen in languages such as Hindi. (20a) is an example of Hindi correlative, and (20b) is its basic structure (Izvorski 1996: 2):

$\begin{aligned} & \text { (20) a. }[\text { jo laRkii khaRii hai }] \text { vo lambii hai. } \text { he } \\ & \text { REL girl standing is DEM tall is } \\ & \text { 'The girl [who is standing] is tall.' } \\ & \text { (Hindi; Srivstav 1991: 639) } \\ & \text { b. }\left[{ }_{\mathrm{CP}}[\text { FREE RELATIVE }]_{\mathrm{i}}\left[{ }_{\mathrm{CP}} \ldots \text { PROFORM }_{\mathrm{i}} \ldots\right]\right]\end{aligned}$

The proform in the matrix clause in (20b) is $v o$ in (20a), not a wh-form. Although a (overt or covert) wh-movement occurs in the relative clause, and an A-bar movement is also assumed to occur in the matrix clause of the construction (Srivastav 1991), the element that undergoes the (overt or covert) A-bar movement is never an overt wh-form. The correlative analysis itself does not restrict the variable in the matrix clause to be a wh-form, although the variable is not an overt wh-form in all well-studied correlatives, as acknowledged by Luo and Crain (2011: 792). Let us assume that it can be a wh-form, although we have not seen such a form yet. If so, the correlative theory might be applicable to some wh-PVCs. But, since the variables in a correlative can be a non-wh form, as seen in (20), whereas the variables in a PdVC must be a wh-form (2.1), the correlative analysis is not sufficient to predict this property of PdVCs.

Chen (2019) also claims that wh-PVCs are correlatives. In her analysis, the variable in the second clause of the construction must be a wh-form because it is a movement copy of the wh-form in the first clause. I have just reported the problems of this movement analysis (see part D above).

Together with the correlative claim, Luo and Crain (2011: 767) also propose that wh-PVCs are "identity statements", which are derived by a covert identity operation in semantics. This assumed operation and the equative analysis argued in this paper seem to aim at similar empirical effects. However, their assumed identity operation "forces expressions to pick up the same referent" (Luo and Crain 2011: 767). It is then not clear how this operation is to derive examples in 2.3 , where the two wh-expressions do not pick up the same referent.

F. The Bound Variable Hierarchy analysis

Like Lin (1996), Pan and Jiang (2015) report certain facts not covered by Cheng and Huang (1996) on wh-PVCs. They propose a Bound Variable Hierarchy, stating that for Chinese conditionals, wh-phrases and reflexives are the 
preferred bound variables and most suitable for appearing in the consequent clauses of a conditional that is not introduced by ruguo 'if', whereas pronouns are preferred to be an E-type pronoun and most suitable for a ruguo/dou conditional (Pan and Jiang 2015: 182). But in their variable use, the relation between a wh-form and a reflexive is not clarified. The contrasts in (21) have not been explained.

$\begin{array}{llllll}\text { a. Shei } & \text { xian } & \text { lai } & \left\{\text { shei }_{i} / *^{*} \text { ziji }_{i}\right\} & \text { xian } & \text { chi. } \\ \text { who } & \text { first } & \text { come } & \text { who/self } & \text { first } & \text { eat }\end{array}$ 'Whoever comes first should eat first.'

b. Mei ge ren dou gei $\{*$ shei/ziji\} mai-le zhang piao. every CL person all for who/self buy-PRF CL ticket 'Everyone bought a ticket for herself.'

In 2.2, we have shown that a PdVC rejects ruguo, and thus it is not a conditional. Also, the variables in the construction are not nominals. This Bound Variable Hierarchy analysis thus does not apply to PdVCs.

G. The question analysis

Calling wh-PVCs wh-conditionals, Liu (2018: 105) proposes that "the wh-clauses in a wh-conditional are genuine questions, while the entire construction encodes a particular relation between them." Similarly, Xiang (2020: 46) states "I propose to treat the two wh-clauses as questions and define the semantics of a wh-conditional as a condition on the short answers of the two questions." Specifically, "some complete true short answer to Q1 is a true short answer to Q2 in every accessible world; defined only if the topical properties denoted by Q1 and Q2 have the same domain." A question approach to wh-PVCs is also seen in Li 2020, 2021. Although these question analyses are for wh-PVCs in general, it is necessary to clarify that a wh-PdVC is not a question construction, and neither of the two wh-clauses of a $\mathrm{PdVC}$ is a question.

First, PdVCs reject expressions that occur in questions only, including embedded questions, e.g., daodi 'the hell' and zenme-gaode 'how come' (Huang 2018). In (22a), bu zhidao 'not know' may select a question, and thus the occurrence of daodi in the complement clause is licensed. In the PdVC in (22b), however, jianchi 'insist' rejects a question complement, and thus daodi is also rejected. In (22c), we see that daodi is rejected in either of the two clauses, indicating that neither clause is a question.
$\begin{array}{llllll}\text { a. Wo } & \text { bu } & \text { zhidao } & \text { ta daodi } & \text { duo } & \text { gao. } \\ \text { I } & \text { not } & \text { know } & \text { he the.hell } & \text { how } & \text { tall }\end{array}$
'I don't know how the hell tall he is.'

b. Wo jianchi women (*daodi) qu da yimiao. I insist we the.hell go get vaccine

'I insist that we go and get vaccinated.' 


c. Zhiming (*daodi) duo gao, Ajiao (*daodi) duo
Zhiming the.hell how tall Ajiao the.hell
'Ajiao is however tall Zhiming is.'

Second, a question never follows its answer immediately, as shown in (23a). In this example, the speaker asks a question, but its answer is to its immediate left. Such an example is not acceptable, because, to a question, "a short answer is a constituent that specifies only the new information" (Xiang 2020: 3). Thus, if the two wh-clauses in the post-suoyi PdVC in (23b) were two questions, the PdVC would not be able to follow the two pre-suoyi sentences immediately, which directly answer the assumed questions. However, the acceptability of the PdVC in (23b) shows that it is not composed of two (embedded) questions.
a. Ajiao you $1.70 \mathrm{~m}$
gao. \#Suoyi
Ajiao
you duo
gao?
Ajiao have $1.70 \mathrm{~m}$ tall therefore Ajiao have how tall
'Ajiao is $1.70 \mathrm{~m}$ tall. \#Therefore, how tall is Ajiao?'

$\begin{array}{llllllll}\text { b. Zhiming } & 1.70 \mathrm{~m} & \text { gao, } & \text { Ajiao } & \text { ye } & 1.70 \mathrm{~m} & \text { gao. } & \\ \text { Zhiming } & 1.70 \mathrm{~m} & \text { tall } & \text { Ajiao } & \text { also } & 1.70 \mathrm{~m} & \text { tall } & \\ \text { Suoyi } & \text { Zhiming } & \text { duo } & \text { gao, } & \text { Ajiao } & \text { (jiu) } & \text { duo } & \text { gao. } \\ \text { therefore } & \text { Zhiming } & \text { how } & \text { tall } & \text { Ajiao } & \text { then } & \text { how } & \text { tall }\end{array}$

'Zhiming is $1.70 \mathrm{~m}$ tall and Ajiao is also $1.70 \mathrm{~m}$ tall. Therefore, Ajiao is however tall Zhiming is.'

Third, the speaker of a wh-question asks for an answer, but the speaker of a whPdVC does not have to care about the content expressed in the left clause of the construction. Recall the -ever effect in our translation (see $\S 1$ ). A PdVC can answer a question targeting at the second clause only, but not the first clause (see [16]). This is not expected if both clauses are questions.

Fourth, the two wh-forms must be identical in a non-degree wh-PVC, but they can be different in a wh-PdVC (2.3). Li (2020: 136) proposes a generalized identity function $f_{\text {id }}$ to capture the morphological identity in the former situation. The absence of this wh-form identity distinguishes wh-PdVCs from other wh-PVCs.

Fifth, if the two post-wh expressions are different in a non-degree wh-PVC, as in (24a), the two wh-expressions must be functionally related in the context (Hua 2000: 185; Li 2020: 135-136). But the two wh-expressions in a PdVC do not have to be functionally related, as seen in (24b). In (24b), the two degrees encoded by the two clauses are accidentally identical, and obviously the hill and the lake are not functionally related to each other. Examples like (24b) lead to a comparison analysis of PdVC (see 4.2.1), but not a question analysis.
a. Women he shenme jiu jiu yong shenme bei. we drink what wine then use what cup 'We should use a type of cup that fits the type of wine one drinks.' (Hua 2000: 184) 
b. Na zuo shan you duo gao, zhe ge hu jiu you duo shen. that CL hill have how high this CL lake then have how deep 'The depth of this lake and the height of that hill are the same.'

Sixth, multiple questions do not have to contain exactly two variables, but a PdVC must contain exactly two wh-variables (2.4). In (25), the embedded question has four wh-variables.

(25) Wo xiang zhidao duo da de panzi yinggai zhuang duoshao I want know how big DE plate should put how.many laobing, yiji duo da de wan yinggai zhuang duoshao jidan. pancake and how big DE bowl should put how.many egg 'I want to know what size of plate should be used to serve how many pancakes and what size of bowl should be used to serve how many eggs.'

(One possible answer: You should use a 6-inch plate for 3 pancakes, an 8-inch plate for 4 pancakes, a small bowl for 3 eggs, and a big bowl for 5 eggs.)

Clearly, the two wh-clauses of a PdVC are different from questions, which, according to Xiang (2016, 2020), can be topical properties, saturated by short answers. Instead, they saturate a comparison quantifier, a new proposal to be argued for in this paper.

\subsection{Summary of the seven analyses}

None of the seven analyses introduced above satisfactorily explains the four distinctive properties of PdVCs reported in $\S 2$. The mismatches between the prediction power of the analyses and the properties of the constructions are summarized in (26).

(26) How the seven analyses predict the four properties of PdVCs

(*! means not predict; *> means not sufficient to predict)

\begin{tabular}{|l|c|c|c|c|}
\hline & $\begin{array}{c}2.1 \text { wh } \\
\text { only }\end{array}$ & $\begin{array}{c}2.2 \text { No } \\
\text { "if" }\end{array}$ & $\begin{array}{c}2.3 \text { Form } \\
\text { variation }\end{array}$ & $\begin{array}{c}2.4 \text { Single } \\
\text { pair }\end{array}$ \\
\hline A. Conditional & $*>$ & $* !$ & & \\
\hline B. ATB movement & $*>$ & & $* !$ & \\
\hline C. Unselective binding & $*>$ & & $*>$ & $*>$ \\
\hline D. Movement copy & $*>$ & & $* !$ & \\
\hline E. Correlative & $*>$ & & & \\
\hline F. Bound Variable Hierarchy & & $* !$ & & $*>$ \\
\hline G. Question & & & $* !$ & $*>$ \\
\hline
\end{tabular}

Moreover, from the perspective of these analyses, the significant and systematic shared properties of PdVCs and degree quantificational constructions (§4) would be accidental, although no previous analysis has addressed the properties. 


\section{Equating achieved by predicate abstraction in PdVCs}

In this section, we start with the relation between duome 'how' questions and duome PdVCs. They are both degree constructions and exhibit the same weak island effects. After clarifying that Mandarin has degree questions, we show why PdVCs are degree quantificational comparison constructions, which are derived by degree abstraction, with paired wh-variables.

\subsection{Duome questions and duome PdVCs}

\subsubsection{The wh-form duome as a degree element}

The goal of this subsection is to show that the wh-word duo(me) 'how' in a PdVC is a degree word independent of the construction. It can occur in a question, as in (27). ${ }^{6}$

Zhiming (you) duo gao? $\quad(\approx[1 \mathrm{a}])$
Zhiming have how tall
'How tall is Zhiming?'

Two facts show that duome is a degree-element (d-element). First, like a d-element, duome must occur with a gradable expression. In (28), yihun 'married' is not gradable, and thus the duome example is not acceptable.

$*$ Zhiming (you) duo yihun?
Zhiming have how married

Gradable expressions denote a relation between entities of appropriate sorts (individuals, states, events, etc.) and degrees (Cresswell 1976; von Stechow 2005). Their semantic type is $<\mathrm{d},<\mathrm{e}, \mathrm{t}>>$. The semantics of gao 'tall' in (27), for example, is (29). If duome must occur with a gradable expression, it ranges over a $<\mathrm{d},<\mathrm{e}, \mathrm{t}>>$ element. $^{\mathrm{T}}$

$$
[[\text { gao }]]=\lambda d: d \in D_{d} \cdot \lambda x: x \in D_{e} \cdot \operatorname{Height}(x) \geq d
$$

Second, one stative may not occur with both duome and another d-word, such as hen 'very'. If duome is a d-element, this restriction is expected, since no two d-elements may be associated with the same gradable element.

6 How can occur in exclamatives. Duome 'how' can also occur in exclamatives with the sentencefinal particle $a$, as in (i). See Trotzke and Giannakidou 2019 for a study of the relation between wh-questions and exclamatives.

(i) Zhiming duome gao a!

Zhiming how tall EXCL

'How tall Zhiming is!'

Also, while how in English is used as either a manner or degree wh-word, duome is used as a d-element exclusively. Instead of duome, the words zenyang, zenme, or ruhe 'how' can be used as a manner wh-word (see [13c]).

7 Different analyses of gradable predicates and degrees (e.g., Schwarzschild and Wilkinson 2002; Moltmann 2009; Anderson and Morzycki 2015; Scontras 2017) do not affect the argumentation here. What is important is that a degree quantifier occurs with gradable expressions in PdVCs. 
(30)

Zhiming duo (*hen) gao?
Zhiming how very tall
'How tall is Zhiming?'

Thus, the wh-form duome is a d-element, and duome questions like (27) are d-questions. However, unlike hen, duome is a wh-word, which means that it may function as an operator and create a predicate out of a clause at LF, like other wh-words.

Note that unlike the Japanese example in (31), no word that means 'degree' occurs in (27). Because of the obligatory occurrence of kurai 'degree' in examples like (31), Japanese has been claimed to have no real d-questions (Beck et al. 2004; cf. Kennedy 2009; Shimoyama 2012; Sudo 2015). According to Beck (2011: 1381), "Degree Semantics Parameter (DSP): A language \{does/does not\} have gradable predicates (type $<\mathrm{d},<\mathrm{e}, \mathrm{t}>>$ and related), i.e., lexical items that introduce degree arguments." One of her diagnostics is to see whether a language has d-questions. It is claimed that Motu and Guarani also have no d-questions. We have shown that unlike these languages, Chinese has d-questions and gradable predicates.

$\begin{array}{lll}\text { John-wa dore-kurai kasikoi no? } & \text { nohn-TOP which-degree smart } & \text { Q } \\ \text { 'To which degree is John smart?' } & \\ \text { (Japanese; Beck et al. 2004: 332) } & \end{array}$

Also, like d-questions in other languages, only negative statives in such questions have an evaluative reading, introducing the presupposition that the property described holds of the target of predication (Lehrer 1985; Kennedy 2001: 47). (32a) is not evaluative, but (32b) is.
a. Zhiming duo gao?
Zhiming how tall

'How tall is Zhiming?' (The speaker does not assume that Zhiming must be tall.)

b. Zhiming duo ai?
Zhiming how short

'How short is Zhiming?' (The speaker assumes that Zhiming is short.)

The syntactic structure of the d-question in (33a) is (33b), and the semantic representation is (33c). In a Mandarin d-question, the wh-form is in situ, but the semantics of the question is the same as its English counterpart.

(33) a. How high is the desk?

b. [Q [how ${ }_{1}$ [the desk is $t_{1}$ high]]]

c. $[[\mathrm{Q}]]$ ( $\lambda$ d.the desk is d-high)

For which d: the desk is d-high

(Beck 2011: 1347)

It is generally assumed that the wh-movement in languages such as English is both semantically driven and EPP-like feature-driven. The former motivation is seen in 
all types of A-bar movement, and the movement is syntactically represented as the dependency of the predicate abstraction feature $[\wedge$ ] (Adger and Ramchand 2005: 173); and the latter motivation is seen in the fact that at least one wh-form must move overtly (Kotek 2019: 2). Assume that the functional head wh-C does not have the EPP-like feature and thus no overt wh-movement is required in Mandarin. But it still has the relevant semantic feature that drives a covert wh-movement. If a whform is treated as a generalized quantifier or operator, it moves to the C-domain. In any case, covert wh-movement is required in Mandarin to return a predicate (see e.g., Xiang 2020; cf. Jacobson 1999; Huang 1982). The covert movement is like that of the in situ wh-element(s) in the multiple wh-constructions in English (Pesetsky 2000; Kotek 2019). Accordingly, I assume that like the English degree how, duome 'how' is a generalized quantifier or operator, and like other wh-forms in Mandarin, it undergoes covert movement to return a predicate.

\subsubsection{The same island effects in the two constructions}

We now report a shared property of duome questions and duome PdVCs: they exhibit the same strong and weak island effects. In the literature, strong island effects in Mandarin have been explained in both syntactic and non-syntactic ways (pragmatic or processing ways), and A-bar dependencies in the language do not always exhibit the full range of strong island effects (e.g., N. Zhang 2002; M. Zhang 2009). However, it is the island effect parallelism between duome questions and duome PdVCs that is important here. Neither the duome question in (34a) (also see Luo 2014) nor the duome PdVC in (34b) shows N-modifier island effect. In contrast, both the duome question in (35a) and the duome PdVC in (35b) show an $\mathrm{N}$-complement island effect (if yaoyan 'rumour' is replaced with baogao 'report' or shuofa 'statement', the judgment remains the same).
a. Ajiao xie-le
duo
chang
de
wenzhang?
Ajiao write-PRF how long DE article

'How long is the article that Ajiao wrote?'

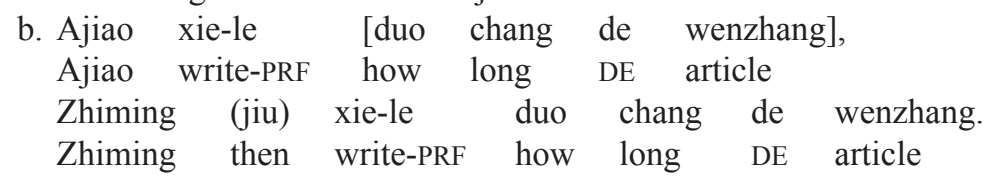

'Zhiming wrote an article as long as the one that Ajiao wrote.'
a. *Ajiao xiangxin [[Lili duo gao] de yaoyan]?
Ajiao believe Lili how tall DE rumour

A possible intended answer: "Ajiao believes the rumour that Lili is $197 \mathrm{~cm}$, but not the rumour that Lili is $187 \mathrm{~cm}$."

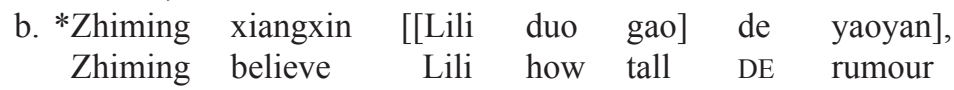
Ajiao (jiu) xiangxin [[Lili duo gao] de yaoyan]. Ajiao then believe Lili how tall DE rumour Intended: 'However tall is Lili in the rumour that Zhiming believes, Ajiao believes the rumour that Lili is that tall.' 
Weak islands, such as negative island, are semantic in nature (see Szabolcsi 2006; Abrusán 2014), as seen in (36a) (Abrusan 2014: 2). Again, duome questions and duome PdVCs behave the same, as seen in (36b) and (36c).

(36) a. *How tall isn't John?

A possible intended answer: "John is not $197 \mathrm{~cm}$ tall."

b. *Ajiao bu duo gao?

Ajiao not how tall

c. *Ajiao bu duo gao, Zhiming (jiu) bu duo gao.

Ajiao not how tall Zhiming then not how tall Intended: 'Ajiao is not n-cm tall, and neither is Zhiming.'

Therefore, PdVCs and d-questions exhibit the same wh-dependency. In the rest of this section, we argue that a PdVC is an equative comparison construction derived by degree abstraction, which is implemented by the wh-dependency. In 4.1.3, we introduce our theoretical background on degree abstraction constructions, and present our proposal. We give our evidence in 4.2 .

\subsubsection{Theoretical background and our proposal}

There are various equative constructions, even in the same language (Rett 2020: 176, 180):

(37) a. Jane is as tall as Bill is.

b. Jane is tall like Bill.

c. Jane is tall; Bill is tall (too).

d. Jane equals Bill in height.

e. Systir min et jafn sister my is equally 'My sister is as tall as I.'
Parameter Marker (PM) equative

Standard Marker (SM)-only equative

Conjoined equative

Predicate equative

stór og ég. [Icelandic]

tall as(SM) I

Adverbial predicate equative

Various elements can be compared: degrees, individuals (Beck et al. 2004; Kennedy 2009; Rett 2020: §5.1), and properties (Kennedy 2009; Alrenga 2010; Rett 2020; Luo and Cao 2019). Rett (2020) shows how the degree comparison construction (or called scalar comparison construction in Alrenga 2010) in (37a) is different from other constructions in (37), which are not degree comparison constructions. According to Stassen (1985) and Rett (2020: 166), the constituents of (37a) are labelled in (38).

$\begin{array}{llllll}\text { (38) } & \text { Jane is } & \text { as } & \text { tall } & \text { as } & \text { Bill } \\ \text { TARGET OF } & \text { PARAMETER } & \text { PARAMETER } & \text { STANDARD } & \text { STANDARD } \\ \text { COMPARISON } & \text { MARKER (PM) } & & \text { MARKER (SM) } & \text { OF COMPARISON }\end{array}$

In such a construction, a set of degrees exists in both the parameter (or called target) and the standard under the comparison. Thus, the comparison is between two degrees. See Heim 2001 and Beck 2011: 1363-1364 for discussions on the quantificational properties of such a construction. Rett's diagnostics for degree quantification will be applied to PdVCs in 4.2. 
As seen in (37), a comparison construction can be built by lexical items (e.g., adverbial and verb), juxtaposed clauses, and degree abstractions (also see Erlewine 2018 for a degree-last strategy in function application). It is generally assumed that a degree comparison construction is derived by degree abstraction. In such a construction, both the standard-denoting clause and the matrix clause provide a predicate of degrees (i.e., they are of type $<\mathrm{d}, \mathrm{t}>$ ). There is a two-place degree quantifier that relates the sets of degrees. I call the quantifier "equative quantifier" (EQ), which is associated to the PM, e.g., the first as in (37a) (Bresnan 1973; Rett 2020). EQ is parallel to the degree quantifier in comparatives, and the latter quantifier is associated to the PM -er or more in English. In (39a), $\geq$, instead of =, is used, because the as...as equatives allow weak readings (see 4.2.5 for details).
a. $[[E Q]]=\lambda D^{\prime} D^{\prime} \cdot \max (\mathrm{D}) \geq \max \left(\mathrm{D}^{\prime}\right)$
b. the type of EQ: $<<\mathrm{d}, \mathrm{t}>,<<\mathrm{d}, \mathrm{t}>, \mathrm{t}>>$
c. EQ is saturated by two $<\mathrm{d}, \mathrm{t}>$ clauses.

How do the parameter clause and the standard clause each become a predicate of degrees? Heim (1985: 3) states that "I will assume here, without argument, that all comparative clauses involve wh-movement of a non-overt wh-element whose closest overt analogue is what." According to Rett (2020: 164, fn. 2), the degree operator in the standard clause of a comparative construction is overt in some dialects of English (e.g., \%Jane is taller than what Bill is). The wh-movement has been recognized in both comparative and equative comparison constructions. The launching site of each wh-movement is a gap in the PM equative in (37a). The gap may not be taken by any non-wh degree term, such as very or somewhat, as seen in (40). This example is similar to our d-question in (30), where two d-terms compete for the same adjective.

(40) The table is as long as it is (*very/*somewhat) wide.

(Alrenga 2010: 160)

Specifically, in a degree quantificational comparison construction, both the standard and the parameter clause are wh-clauses with a degree gap. The gap is the trace of a wh-moved operator interpreted via predicate abstraction. In English, the standard clause is extraposed rightward, and its lexical predicate that is identical to the one in the parameter clause is deleted. (41) has its semantics in (42).

(41) Jane is as tall as Bill is.

$$
\begin{aligned}
{[[(41)]] } & =[[E Q]](\mathrm{D} 2)(\mathrm{D} 1) \\
& =[[\mathrm{EQ}]](\lambda \mathrm{d} 2 . \text { Bill is d2-tall })(\lambda \mathrm{d} 1 \text {.Jane is d1-tall }) \\
& =1 \Leftrightarrow \max (\lambda \mathrm{d} 1 \text {.Jane is d1-tall }) \geq \max (\lambda \mathrm{d} 2 . \text { Bill is } \mathrm{d} 2 \text {-tall })
\end{aligned}
$$

Back to PdVCs. They are neither conditional constructions (2.2; cf. 3.1A) nor question constructions (cf. 3.1G). Also, although there is no lexical item in the constructions to express any equative meaning, the presence of the paired wh-forms leads to an equative reading. We propose that the duome or duoshao 
wh-forms are the wh-forms that Heim has expected to see in a comparison construction. They are the same d-words that occur in a d-question, surfacing at the same variable position of the covert wh-movement (since choosing a particular theory to represent the semantics of such d-words is not the focus of this paper, I will not try to elaborate the semantics here). The movement creates a predicate from the clause. Thus, a PdVC has the same semantics as a degree equative like (37a) in English. Both have wh-movement, although the former has overt variables, whereas the latter does not (see 2.1). Both have a degree quantifier for the comparison. There is one degree variable in the standard clause and one variable in the matrix clause (2.4). But there is neither extraposition nor obligatory deletion (cf. Kennedy 2002) in a PdVC.

In a comparison construction, it is the parameter, rather than the standard, that is asserted. In a PdVC, the left clause is the standard-denoting clause, and the right one is the parameter-denoting clause. Thus, the right clause is asserted (cf. 3.1B).

In some languages, it is the SM that is in a HOW-form (Haspelmath 2015: 3; Rett 2020: 175). But not all constructions with such a single wh-form pass the diagnostics for a degree quantification construction (see Rett 2020). In the next subsection, I use four diagnostics to identify the duome PdVC as a degree abstraction construction.

\subsection{Duome PdVCs as degree abstraction equatives}

\subsubsection{Subcomparison}

Subcomparison, such as the comparative in (43a) and (44a), and the equative in (43b) and (44b), is a well-recognized diagnostic for degree abstraction (Bresnan 1973; Kennedy 2002; Lechner 2001). A PdVC may compare degrees on different dimensions, as seen in (45). Importantly, the two unlike variables do not have to be functionally related (cf. (24a) and (24b)).

(43) a. The space telescope is longer than it is wide. (Kennedy 1999, 2001)

b. The table is as long as it is wide. (Alrenga 2010: 160)

(44) a. I brought more bananas than you brought apples.

b. I brought as many bananas as you brought apples. (Mendia 2020: 621)

(45) a. Na ge beizi duo shen, zhe zhi xiguan jiu duo chang. that CL cup how deep this CL straw then how long 'This straw is however long as that cup is deep.'

b. Na kuai boli duo hou, zhe tiao jiaodai jiu duo kuan. that chunk glass how thick this CL tape then how wide 'This tape is however wide as that piece of glass is thick.' 
c. Ai jia-ren you duo shen, juli jiu you duo yuan. love family-person have how deep distance then have how far 'The distance you keep from your family members is however far as your love for them is deep.'

(Ziyou Shibao [Liberty Times], March 28, 2020; people were encouraged to keep a social distance in the coronavirus pandemic)

Subcomparion is a degree comparison of gradable expressions on different dimensions. Each dimension must provide a set of degrees and the degrees are related by a degree quantifier. Kennedy (2002: 571) claims that for English comparatives, subcomparison and "normal" degree comparison constructions have structurally identical LF representations.

According to Beck et al. (2004) and Beck (2011:1384), a language \{does/ does not $\}$ have binding of degree variables in the syntax. They call this Degree Abstraction Parameter (DAP). They state that if a language has a subcomparison construction, it is a +DAP language. In fact, although English is assumed to be a +DAP language, not all comparison constructions allow subcomparison (cf. [37]). Likewise, the fact that some comparative constructions in Mandarin disallow subcomparison does not entail that PdVCs must also disallow such a comparison. The examples in (45) are our new observations. Since PdVCs allow subcomparison, they are degree quantificational constructions.

4.2.2 The rejection of a degree demonstrative

In English, the degree demonstratives yea and yay mean 'so' or 'to this extent' (e.g., John is yea tall. Rett 2015: 2). That also has this use (e.g., that cold; Beck 2011: 1380). But they may not occur in the parameter clause of a degree quantificational equative, as seen in (46).

(46) *Jane is as $\{$ yea/that $\}$ tall as Bill is.

(our informant)

Mandarin also has the degree demonstratives name 'that degree' and zheme 'this degree' (Lü 1999: 400, 660), which are associated with a gradable expression exclusively, as seen in (47a). They are banned in a PdVC, as seen in (47b).
a. Zhiming (you) name gao.
Zhiming have that tall
'Zhiming is that tall.'
b. *Zhiming duo gao Ajiao (jiu) name gao.
Zhiming how tall Ajiao then that tall

Degree demonstratives are allowed in equatives in Romanian, Catalan, Slovenian, Spanish (Rett 2020: 187 [70], 193 [82], 198-199; Crnic and Fox 2019):
a. Gianni è tanto
Gianni is that.much(PM)
alto quanto
Pietro.

'John is as tall as Peter.'

[Italian] 
$\begin{array}{llllll}\text { b. Irina este tot atît } & \text { de înaltă } & \text { ca } & \text { şi } & \text { Maria. } \\ \text { I is all that.much(PM) } & \text { of all } & \text { as(SM) } & \text { also } & \text { Maria } \\ \text { 'Irina is as tall as Maria.' } & & & & & \text { [Romanian] }\end{array}$

Rett (2020) argues that such demonstrative equatives are not degree quantificational. She claims that the constructions involve degree anaphora in the matrix clause. She (Rett 2020: 195) points out that while degree quantifiers relate two sets of degrees, degree demonstratives are directly referring. Such constructions are like correlatives, which have only one operator movement; (49) illustrates the structure of (48a). The index on that shows that the demonstrative is anaphoric to the degree $d$ in the embedded clause. Izvorski (1996: 10) argues that in a correlative, the proform in the matrix clause also undergoes an operator movement. But, importantly, the two operator movements (the one inside the relative clause and the one in the matrix clause) do not link to the same quantifier, unlike in a degree comparison construction.

(49) [ $_{\mathrm{CP}}$ Gianni is $\left[{ }_{\mathrm{CP}} \mathrm{OP}_{d}\right.$ how much Pietro è $d_{i}$-tall] that tall] (for [48a]; Rett 2020: [83])

If the rejection of a demonstrative in the matrix clause is a signature property of a quantificational comparison construction, we can explain why a PdVC has a pair of wh-form (2.1): a wh-form cannot be replaced with another form such as a demonstrative because a PdVC is a degree quantificational comparison construction.

\subsubsection{Embedding}

A degree quantification comparison construction allows embedding, as seen in the as ... as equative in (50). In (50a), the comparison is between the matrix predicate and an embedded predicate in the standard clause; and in (50b), the comparison is between the attributives of the objects of the two verbs, rather than the predicates of the two clauses.

(50) a. John is as tall as Mary thinks that he is.

b. John wrote a paper as short as Mary did.

PdVCs also allow embedding. In (51a), the standard of the comparison is embedded in the complement of the verb juede 'think'; in (51b), the parameter of the comparison is embedded in the complement of the verb caixiang 'guess'; and in (51c), the standard is embedded in the complement of the verb yunxu 'allow', and the parameter is embedded in the complement of the verb dasuan 'plan'. The example in (52) parallels (50b), where the attributives of the objects of the verbs in the two clauses are compared.

a. Ni juede [Zhiming duo gao], ta (jiu) duo gao.
you think Zhiming how tall
'Zhiming is howevertall you think he is.'

b. Zhiming duo gao, wo caixiang [Ajiao jiu duo gao]. Zhiming how tall I guess Ajiao then how tall 'I guess Ajiao is however tall Zhiming is.' 


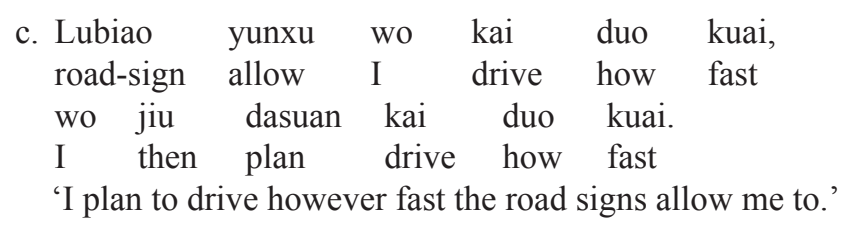

(52) Ajiao xie-le $\quad[$ duo chang de wenzhang],
Ajiao write-PRF how long DE article
Zhiming jiu xie-le duo chang de wenzhang. $\quad(=[34 \mathrm{~b}])$
Zhiming then write-PRF how long DE article
'Zhiming wrote an article as long as the one that Ajiao wrote.'

If in both the standard and the parameter clause there is an operator movement, the long-distance movement chain is not a surprise. However, there is a contrast between the English comparatives and the Mandarin bi-comparatives: the former allows embedding, whereas the latter does not, as seen in (53) and (54) (Erlewine 2018: [70], [71], [77], [79b]).

(53) a. John is taller than [Mary thinks that he is _].

$\begin{array}{ccccc}\text { b. * } \text { Yuehan }_{\text {i }} & \text { bi } & \text { [Mali renwei } & \text { ta gao]. } \\ \text { John } & \text { BI } & \text { Mary thinks he tall }\end{array}$

Intended: 'John is taller than Mary thinks he is.'

(54) a. John wrote [a longer paper] than Mary did.

b. *Zhangsan bi Lisi xie-le [(yi pian) chang (de) lunwen].

Zhangsan BI Lisi write-PRF one CL long DE paper

Intended: 'Zhangsan wrote a longer paper than Lisi did.'

According to Erlewine (2018: 456, 472f), the contrast shows that the English examples in (53a) and (54a) are derived by degree abstraction whereas the Mandarin bi-comparatives are not. Basically, the possible embedding indicates the possible degree abstraction, and the impossibility of such embedding must be explained in a different way (see Erlewine 2018 for his analysis of the Mandarin bi-comparative constructions; cf. Lin 2019). We have seen that PdVCs behave like degree comparison constructions in English in this embedding aspect.

4.2.4 Negative Polarity Item (NPI) licensing

The standard clause of an as...as equative licenses an NPI (Alrenga 2010; Beck 2011: 1357).

(55) a. Her mind is as quick as it ever was.

(Alrenga 2010: [26c])

b. Jim is as competent as anyone here could possibly be.

(Alrenga 2010: [26d])

The standard clause of a PdVC also licenses an NPI use (i.e., an indefinite use) of a wh-word (Huang 1982: Ch. 4; Li 1992). In (56), shenme 'what' is interpreted as 'any'. 
(56)

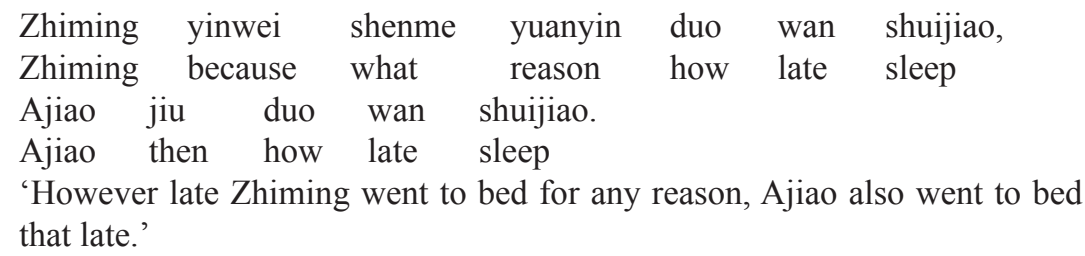

The conditions to license an NPI in comparison constructions have been discussed in the literature. Following Ladusaw (1979), von Stechow (1984) proposes a downward entailment (DE) monotonic context theory. ${ }^{8}$ Giannakidou $(1994,2011)$ proposes a nonveridical context theory on NPI-licensing, and Duffley and Larrivée (2019) give a more refined pragmatic theory, showing that an NPI is licensed by at-issue meaning. Structurally speaking, the standard clause licenses an NPI (or a free choice item, as claimed by Giannakidou and Yoon 2010), because it is bound by a two-place quantifier and it satisfies the relevant pragmatic conditions. If the left clause of a PdVC occurred alone, as a wh-question, it would not license an NPI, as shown in (57). Although I have no new theory on NPIs, the licensing of an NPI in a PdVC, as seen in (56), indicates the occurrence of a comparison quantifier, as in the examples in (55).

(57) Zhiming yiwei \{*shenme/na\} yuanyin duo wan shuidejiao?(cf. [56]) Zhiming because any/that cause how late sleep

'How late did Zhiming go to bed, because of that?'

The above four diagnostics show that a PdVC is a degree quantificational construction. Unlike PdVCs, two other equative constructions in Mandarin, the X-you-Y-G equatives (Xie 2014), as in (58a), and the yiyang 'same' or tongyang 'same' equatives (phrasal approach in Gu and Guo 2015, clausal approach in Luo and Cao 2019), as in (58b), do not pass these diagnostics, and thus they are not degree quantificational constructions (see Zhang 2019; Luo and Cao 2019; Xie 2014). The former is analyzed as a degree anaphor construction in Zhang 2019, and the latter is analyzed as a non-quantificational comparison construction in Luo and Cao 2019.
a. Ajiao
you
Zhiming
gao.
(Xie 2014: X-you- $Y-G$ constr.)
Ajiao
have Zhiming
tall
'Ajiao is as tall as Zhiming.'

8 Giannakidou and Yoon (2010: §1) state "yet Larson (1988), and Schwarzschild and Wilkinson (2002) show that the DE scheme is not validated in the comparative, but the upward entailing is, as shown below". Their examples are in (i) and (ii). But it has been pointed out to me that Giannakidou and Yoon's discussion mixes NPIs with other issues, such as free choice items and epistemic indefinites.

(i) a. John is taller than some professional athletes are. $-/ \rightarrow$ b. John is taller than some professional basketball players are.

(ii) a. John is taller than some professional basketball players are. $\rightarrow$ b. John is taller than some professional athletes are. 
b. Ajiao xiang Zhiming yiyang gao. (Luo and Cao 2019: yiyang constr.) Ajiao similar Zhiming same tall

'Ajiao is as tall as Zhiming.'

\subsubsection{Two more properties}

The PdVC and the English as...as comparison construction share two more properties. First, their positive forms lack an evaluative reading. A construction is evaluative if it requires that a degree exceed a contextually valued standard. The lack of an evaluative reading of (59a) can be seen in their compatibility with the negation of the relevant antonym (Bierwisch 1989; see Rett 2020: $\S 4.1$ for a discussion of other kinds of equatives with respect to this issue). In this respect, a degree comparison is similar to a degree question (see [32]).

(59) a. Jane is as tall as Bill, but she is short.

b. Jane is as short as Bill, \#but she is tall.

PdVCs behave the same, as seen in (60). The positive version in (60a) is not evaluative, but the negative one in $(60 \mathrm{~b})$ is.

a. Zhiming duo gao, Ajiao jiu duo gao.
Zhiming how tall Ajiao then how tall
$\begin{aligned} & \text { Dan ta haishi hen ai. } \\ & \text { but she still }\end{aligned}$

'Ajiao is however tall Zhiming is. But she is still very short.'

b. Zhiming duo ai, Ajiao jiu duo ai. Zhiming how short Ajiao then how short

\#Dan ta haishi hen gao.

but she still very tall

'Ajiao is however short Zhiming is. \#But she is still very tall.'

Second, the as...as equative may have a weak reading in certain contexts (von Stechow 1984; Schwarzschild 2008; Beck 2011; Rett 2020), as seen in (61a), and so may a PdVC, as seen in (61b). Also, as expected, the yiyang equative, as in (58b), rejects a weak reading (see Hsieh 2020: [7], not given here).

(61) a. S1: Bill doesn't want a bodyguard who is shorter than he is. Is Jane a possibility?

S2: Yes, Jane is as tall as Bill is (in fact she's taller).

(Rett 2020: 165 [7], 180 [51a])

b. Zhiming duo gao, Ajiao jiu duo gao. (Shijishang Ajiao geng gao.) Zhiming how tall Ajiao then how tall actually Ajiao more tall 'Ajiao is however tall Zhiming is. (Actually, Ajiao is taller.)'

We conclude that like an as... as construction in English, a duome PdVC is a degree quantificational equative construction. 


\subsubsection{Explaining the absence of a factor modifier}

Unlike other types of equatives, a degree quantificational equative allows a factor modifier, such as twice in (62) (Rett 2020: 182 [54]). ${ }^{9}$

(62) a. Jane is twice as tall as Bill.

b. Jane is (*twice) tall like Bill.

PM equative

c. Jane is (*twice) tall; Bill is tall (too).

d. Jane (*twice) equals Bill in height.

SM-only equative

conjoined equative

predicate equative

A factor modifier modifies sets of degrees (Schwarzschild 2005). In the absence of such a modifier, the semantics of the degree quantifier EQ is (63a) $(=[39 \mathrm{a}])$, but in the presence of such a modifier, as in (62a), the semantics of the EQ is (63b) (cf. Beck 2011: 1349).
a. $[[\mathrm{EQ}]]=\lambda \mathrm{D} 1 . \lambda \mathrm{D} 2 \cdot \max (\mathrm{D} 2) \geq \max (\mathrm{D} 1)$
b. $\left[\left[\mathrm{EQ}_{\mathrm{diff}}\right]\right]=\lambda \mathrm{d} \cdot \lambda \mathrm{D} 1 . \lambda \mathrm{D} 2 \cdot \max (\mathrm{D} 2) \geq \mathrm{d} * \max (\mathrm{D} 1)$

A PdVC, however, rejects a factor modifier:

$\begin{array}{lllllll}\text { *Zhiming duo gao, Ajiao jiu } & \underline{\text { liang-bei }} \text { duo gao. } \\ \text { Zhiming how tall } & \text { Ajiao then two-time how tall }\end{array}$

Note that unlike [-DSP] languages (see 4.1.1) such as Washo (Deal and Hohaus 2019), Mandarin allows a differential expression in a comparative, as seen in (65).

Ajiao bi Zhiming gao liang gongfen.
Ajiao than Zhiming tall two centimetre
'Ajiao is two centimetres taller than Zhiming.'

The rejection of a factor modifier in a PdVC, which is degree quantificational, seems surprising. Our account is that a factor modifier denotes a quantity, and thus it triggers a quantifier intervention for overt wh-forms. The generalization of an intervention is that an intervener cannot c-command an overt wh-phrase, as shown in (66a); in order to yield an interpretable structure, a wh-form must overtly move above the intervener, as shown in (66b).
a. $*\left[{ }_{\mathrm{CP}} \mathrm{C} \ldots[\right.$ Intervener $[\ldots$ wh $\left.\ldots]]\right]$
b. $\left[{ }_{\mathrm{CP}} \mathrm{C} \ldots[\mathrm{wh}[\right.$ intervener $\left.[\ldots \mathrm{t} \ldots]]]\right]$

(Kotek 2019: 5)

According to $\mathrm{Li}$ and Law (2016: 235), "while focus-sensitive operators are consistent intervention triggers across languages, quantifiers constitute a much more heterogeneous class (see Beck 2006, p. 10). What counts as an intervener in a language may very well be a non-intervener in other languages" (also Tomioka

9 The noun factor means a number that when multiplied with another produces a given number. 
2019: 11). They discuss a few cross-linguistic variations in quantifier intervention, and report that in Mandarin, strong quantifiers do not, but weak quantifiers do, trigger quantifier intervention. For example, shei 'who' is not affected by the strong quantifier gege 'each' in (67a), but is by the weak quantifier xuduo 'many' in (67b).
a. Gege xuesheng jian-le shei?
each student meet-PRF who
'Who was the person $\mathrm{x}$ such that each student met $\mathrm{x}$ ?'
b. ?*Xuduo xuesheng jian-le shei?
many student meet-PRF who

Intended: 'Who was the person $\mathrm{x}$ such that many students met $\mathrm{x}$ ?'

A factor modifier is also a weak quantifier. Thus, liang-bei 'two-times' is an intervener for $d u o$ (me) in (64). This explains the unavailability of a factor modifier for PdVCs. In the English equative in (62a), however, twice does not c-command any overt wh-form; similarly, in the Mandarin comparative in (65), liang gongfen 'two centimetres' does not c-command any overt wh-form, either; and thus the acceptability of these examples is expected. The absence of a factor modifier in a PdVC is compatible with Kotek's and Li and Law's conclusions.

\subsubsection{Section summary}

The similarities of the as...as equatives in English and PdVCs are summarized in (68). Like the former, the latter is also a degree quantificational equative. The unavailability of a factor modifier in PdVCs can be a quantifier intervention for overt wh-forms (cf. Rett 2020).

(68) Shared distinctive properties of degree quantificational constructions

\begin{tabular}{|l|c|c|c|c|}
\hline equative & subcomparison & $\begin{array}{c}\text { demonstrative } \\
\text { blocking }\end{array}$ & embedding & $\begin{array}{c}\text { NPI- } \\
\text { licensing }\end{array}$ \\
\hline as... as... & $\checkmark$ & $\checkmark$ & $\checkmark$ & $\checkmark$ \\
\hline PdVC & $\checkmark$ & $\checkmark$ & $\checkmark$ & $\checkmark$ \\
\hline
\end{tabular}

In this analysis, it is the null EQ quantifier and not any other quantifier that licenses the wh-forms in a PdVC. Thus, the construction is neither a conditional nor an interrogative construction $(2.2$, cf. 3.1A, G). Also, the covert wh-movement in both clauses ensures the presence of a wh-variable in each clause (2.1). Moreover, since it is degrees that are compared, the forms of the non-degree parts in the two clauses do not have to be identical (2.3). Finally, since a PdVC is a quantificational comparison, the unique wh-variable in the standard clause correlates with exactly one wh-variable in the parameter clause (2.4).

In the next subsection we discuss another type of PdVCs, the duoshao type. Their properties parallel those of the duome type. 


\subsection{Duoshao PdVCs as degree abstraction equatives}

Gradable or measurable expressions can be any syntactic categories (Wellwood 2015). In a PdVC, the wh-form can also be duoshao 'how much, how many', in addition to duome 'how'. Both duome and duoshao select a gradable expression. They differ in their c-selection: the former rejects a nominal, whereas the latter requires a nominal. Here are two duoshao PdVCs. ${ }^{10}$

(69) a. Zhiming mai-le duoshao kafei, Ajiao jiu mai-le duoshao kafei. Zhiming buy-PRF how.much coffee Ajiao then buy-PRF how.much coffee 'Ajiao bought as much coffee as Zhiming did.'

b. Zhiming pao-le duoshao (juli/shijian), Ajiao jiu pao-le Zhiming run-PRF how.much distance/time Ajiao then run-PRF duoshao (juli/shijian). how.much distance/time 'Ajiao ran as much as Zhiming did.'

In 4.2, we used four diagnostics to identify duome PdVCs as degree quantificational constructions. We now use the same four diagnostics to show the same status of the duoshao version. (70a) shows that subcomparison is possible (cf.[44b]); (70b) shows that the construction rejects a degree demonstrative; $(70 \mathrm{c})$ shows that the standard can be embedded; and (70d) shows that an NPI can be licensed in the standard clause.

(70) a. Na zuo shan gao duoshao gongchi, zhe ge hu jiu that CL hill height how.many meter this CL lake then shen duoshao gongchi.

depth how.many meter

'The depth of this lake and the height of that hill have the same number of meters.'

b. *Zhiming mai-le duoshao kafei, Ajiao jiu mai-le Zhiming buy-PRF how.much coffee Ajiao then buy-PRF naxie kafei. that coffee

c. Shangdian yunxu mei ge guke mai duoshao nai-fen, shop allow every CL customer buy how.much milk-powder Ajiao jiu mai duoshao nai-fen. Ajiao then buy how.much milk-powder 'Ajiao buys milk-powder as much as the shop allows each customer to buy.'

10 Another wh-word $j i$ 'how many' is always followed by a unit word in a nominal. It can be used in PdVCs, as in (i). The ji PdVCs behave the same as the duoshao ones. In this paper, I discuss the duoshao version only.

(i) Zhiming ji dian qichuang, Ajiao jiu ji dian qichuang. Zhiming how.many hour get.up Ajiao then how.many hour get.up 'Ajiao gets up at the same time as Zhiming does.' 
d. Zhiming yinwei shenme yuanyin he-le duoshao jiu Zhiming because what reason drink-PRF how.much alcohol Ajiao jiu he duoshao jiu. Ajiao then drink how.much alcohol 'How much alcohol Zhiming drank for any reason, Ajiao also drank that much alcohol.'

Recall that a quantificational equative construction does not contain any equative adverb such as equally or same (see $\S 1,4.1 .3$, and 4.2.4). A PdVC also does not contain any equative element such as tongyang 'same'. (71) contains tongyang, and the possible occurrence the demonstrative name 'that' in the matrix clause does not challenge our claim that a PdVC rejects a demonstrative in the matrix clause.

(71) Kan Lisi juan-le duoshao qian, wo (jiu) ye juan see Lisi donate-PRF how.much money $I$ then also donate tongyang name duo qian. same that much money

'However much Lisi donated, I will donate the same much money.'

Moreover, like a duome PdVC, a duoshao PdVC also allows a weak reading.

Zhiming zhuan duoshao, Ajiao jiu zhuan duoshao.
Zhiming earn how.much Ajiao then earn
Shijishang Ajiao zhuan gengduo.
in.fact
'Ajiao earns as much as Zhiming does. In fact, she earns more.' ${ }^{11}$

Finally, like a duome PdVC, a duoshao PdVC also rejects a factor modifier, presumably, because of the same quantifier intervention.

(73) *Zhiming mai-le duoshao kafei, Ajiao jiu mai-le liang-bei Zhiming buy-PRF how.much coffee Ajiao then buy-PRF two-time duoshao kafei. how.much coffee

We conclude that duoshao PdVCs have the same structural properties as duome PdVCs. They both are degree quantificational equatives.

11 The example in (i) (cf. Liu 2018: 120) (my translation) can be easily followed by either (ii) or (iii). This flexibility also shows that the PdVC in (i) allows a weak reading.

(i) Chi duoshao, jiu cheng duoshao. eat how.much then fill how.much 'Fill the plate with the amount of food that you will eat.'

(ii) Bie duo-cheng. don't more-fill 'Don't fill more.'

(iii) $\mathrm{Ni}$ ye keyi duo-cheng yidian, ruguo ni xiang dai-zou. you also can more-fill a.bit if you want take-away 'You can also fill more if you want to take the food away.' 


\subsection{Comparison of non-commensurable gradable expressions}

The degree quantificational equative status of the two types of PdVCs is further supported by the fact that they may contain gradable but incommensurable expressions.

(74) a. Nashihou tianqi duo leng, wo jiu chuan duo hou de yifu. then weather how cold I then wear how thick DE clothes 'At that time, I wore clothes as thick as the weather is cold.'

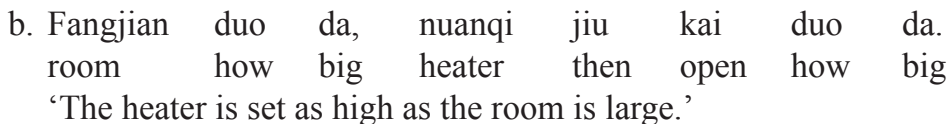

(75) Chi duoshao, (jiu) fu duoshao.

eat how.much then pay how.much

'Pay as much (money) as (much food) you eat.'

In (74a), for example, coldness and thickness are not commensurable. We can compare this situation with the subcomparison examples in (45). The two situations are similar in that the comparison is between two different dimensions. Beck (2011: 1346) states that "in order to get an acceptable subcomparative, choose your example in such a way that the two adjectives operate on the same scale" (e.g., centimeter for both the length and width dimensions). But this is not the case in (74) and (75), where the scales of the two dimensions are different.

Such examples are similar to the indirect comparison discussed by Bale (2008), e.g., Esme is more beautiful than Einstein is intelligent. Bale (2008) proposes a detailed unified analysis to cover both subcomparison and indirect comparison. He claims that they both involve a scale of universal degrees that are isomorphic to the rational (fractional) numbers between 0 and 1. Importantly, "the connection between the individuals being compared and universal degrees involves two steps. First, individuals are mapped to a value on a primary scale that ranks individuals with respect to the gradable property (whether it be height, beauty or intelligence). Second, the value on the primary scale is mapped to a universal degree that encodes the value's relative position on the primary scale" (Bale 2008: 1). If we use this theory to describe the equation in (74b), for example, our understanding is the following. If the heater has only three scales (weak, mild, and strong), we take these scales as primary scales of the heater. If the sizes of the rooms under our consideration are between $8 \mathrm{~m}^{2}$ and $40 \mathrm{~m}^{2}$, we can first roughly rank the sizes into three primary levels: say, $\mathrm{L} 1$ is smaller than $20 \mathrm{~m}^{2}, \mathrm{~L} 2$ is between $20 \mathrm{~m}^{2}$ and $30 \mathrm{~m}^{2}$, and L3 is bigger than $30 \mathrm{~m}^{2}$. Then, both the weak scale of the heater and L1 of the room size are mapped to $1 / 3$ on the universal scale; both the mid-scale of the heater and L2 of the room size are mapped to 2/3 on the universal scale; and finally, both the strong scale of the heater and L3 of the room size are mapped to $3 / 3$ on the universal scale. In this way, an equation is achieved between the two apparently incommensurable dimensions. Like subcomparison, indirect comparison also clearly shows that it is degrees that are compared. 
In this section, using the same four diagnostics, we have argued that the two types of PdVCs (i.e., duome and duoshao PdVCs) are both degree quantificational constructions, and that the wh-forms are degree variables, bound by a null EQ. ${ }^{12}$

\section{The general complementation structure of PdVCs}

I now propose a general syntactic structure for both types of PdVCs: the first whclause (CP1) and second one (CP2) are the Spec and Complement of a functional head C3, respectively; $\mathrm{C} 3$ is realized by the null EQ. This EQ denotes an equative relation. As stated in 4.1.3, the wh-forms in both clauses undergo covert movement, creating clausal predicates that are selected by the EQ. Following Kotek (2019), I use dotted line for covert movement. The general syntactic structure of a PdVC is in (76). The null EQ is a two-place quantifier, selecting two clausal predicates. The two clauses are both type $<\mathrm{d}, \mathrm{t}\rangle$, and EQ is type $\langle\mathrm{dt},\langle\mathrm{dt}, \mathrm{t}\rangle>$. The structure of the PdVC in (77a) is (77b).

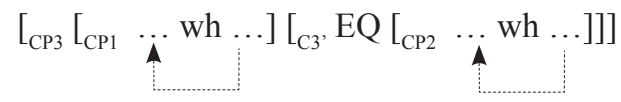
a. Zhiming
duo
gao, Ajiao
duo
gao.
$(=[1 \mathrm{~b}])$
Zhiming
how
tall Ajiao
how
tall

'AJ is however tall ZM is.'

b. $[[\mathrm{CP} 3]]=1 \Leftrightarrow \max (\lambda \mathrm{d}$.AJ is d-tall $) \geq \max (\lambda \mathrm{d} . \mathrm{ZM}$ is d-tall $)$
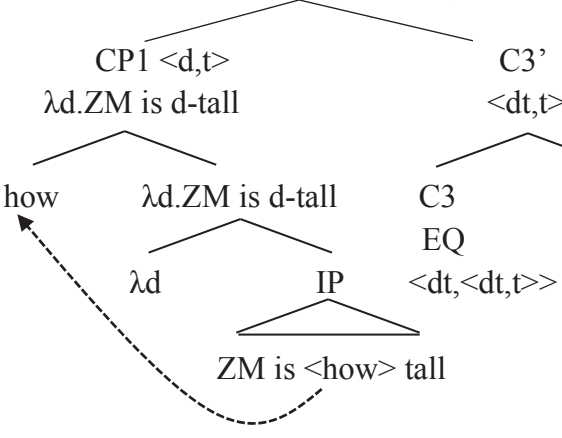

$\mathrm{CP} 2<\mathrm{d}, \mathrm{t}>$

$$
\lambda \text { d.AJ is d-tall }
$$

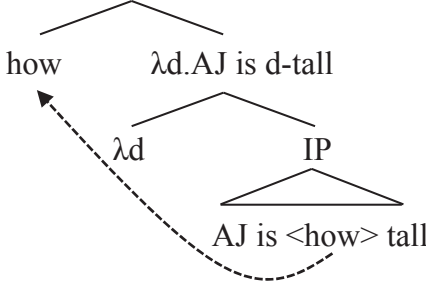

12 It needs to be mentioned that Erlewine's (2018) Degree-Last approach to the bi-comparatives in Mandarin, which have no degree abstraction, does not apply to PdVCs. This is because the $b i$ comparatives reject embedding (see (53b) and (54b)), but PdVCs allows embedding. If the clause that has a gradable predicate is type $<\mathrm{d}, \mathrm{t}>$ directly, it cannot be merged with a higher verb. As pointed out by him on p. 450, "Of course, this approach would not help in the more general case for English: examples with embedded standards ... cannot be analysed in this way without degree abstraction." PdVCs allow embedded standards, as well as embedded targets, similar to the as... as equatives (see 3.2.3). Thus, the formal properties of PdVCs are similar to English comparative constructions, in which long-distance wh-movement may start from an embedded clause. 
The standard clause of a comparison construction has been analyzed as an adjunct in the literature (e.g., Bhatt and Takahashi 2011: 584; Erlewine 2018). However, as pointed out by den Dikken (see Giannakidou and Yoon 2011: 641), the adjunct analysis does not capture the argument status and thus the obligatory presence of the standard clause. My proposed complementation structure avoids this problem (also see Vanden Wyngaerd et al. 2020: 14 for the possibility that the standard expression of a comparison construction is base-generated in the Spec position, and see Hankamer and Mikkelsen 2021: 504 (93) for an analysis in which the parameter and the standard are the Spec and complement of the same Deg head). Note also that in a PdVC, the standard clause is not extraposed, unlike that of the English as... as equatives.

In this section, I have given a general complementation syntactic structure of PdVCs.

\section{Conclusions and contributions}

This paper has studied two types of wh-PdVCs in Mandarin, the duome 'how' type and the duoshao 'how much/many' type, and argued that they both are equative constructions, derived by predicate abstraction. In wh-PdVCs, the wh-forms duome and duoshao are degree variables. A null quantifier EQ has been proposed to cover the two types of quantificational equative comparison.

This EQ, like the quantifier in the as...as equatives in English, allows subcomparison, licenses an NPI in a standard clause, and allows clause embedding; and on the other hand, it requires the presence of a pair of wh-variables distributed in the two clauses, and thus blocks a demonstrative form in the variable positions.

In this approach, the two wh-clauses of a PdVC saturate the null EQ quantifier, which has no question feature. This explains why the wh-forms in a PdVC do not have a question reading. The construction is not only systematically similar to the as ... as equatives in English, but also systematically different from other PVCs in Mandarin. First, since the first clause denotes the standard of a comparison, the analysis explains why the clause cannot be selected by a conditional complementizer, unlike in other PVCs in the language (2.2). Second, the whmovement in both clauses ensures the presence of a wh-variable in the clause. This explains why the variable in each of the clauses must be a wh-form (2.1). Third, since the construction is a quantificational comparison one, only degrees are compared. Thus, it is possible for the two wh-variables to be in different forms, unlike in other PVCs in the language (2.3). Finally, since in a quantificational comparison, the unique wh-variable in one clause correlates with the unique whvariable in the other clause, the wh-variables thus occur in one pair only, unlike in other wh-PVCs in the language (2.4).

The paper has made the following contributions to the degree grammar.

(1) It is possible for both clauses of a comparison construction to have a wh-form. Wh-forms have been found as an SM in equatives in some 
languages (Rett 2020: 175), but paired wh-forms have not been recognized in typological studies of comparison constructions (Haspelmath and Buchholz 1998; Henkelmann 2006; Haspelmath 2015; Rett 2020), although the available theories predict the possibility of their existence. In a PdVC, a newly recognized degree quantificational construction, a wh-form occurs in each of the two d-variable positions. We thus see a direct link between wh-dependencies and the degree grammar.

(2) In a PdVC, neither SM nor PM occurs. This research clarifies an issue raised by Rett (2020: 172 fn. 5): "while degree quantifiers are used to model the contribution of a comparative parameter marker in explicit equatives, it's not obvious that the absence of a comparative parameter marker entails the absence of a degree quantifier." We have shown that the entailment does not exist. In the as ... as equatives in English, the PM as occurs in the same position as the PM more in comparatives. In Mandarin, there is no counterpart of the $\mathrm{PM}$ more or -er in comparatives. It is thus not a surprise that there is no overt $\mathrm{PM}$ in the PdVC equative, either.

(3) The typological classification in comparison grammar (as in other parts of grammar) is not language-oriented; instead, it should be constructionoriented. See (37). It is not true that Mandarin lacks degree abstraction (cf. Beck et al. 2004: 339; Beck 2011: 1385).

(4) When one uses the availability of a factor modifier as a diagnostic for degree quantification, one should use it with care: there are different reasons for its absence. The intervention effect can block a factor modifier in degree quantification.

\section{Acknowledgments}

Early versions of this work were presented in Nanjing and discussed with many people. The author thanks Chensheng Liu, Jowang Lin, Thomas Grano, Sze-Wing Tang, and Qiongpeng Luo. She also received help with the data and other kinds of support from Junghsing Chang, James Myers, Jiun-Shiung Wu, and Hsuan-Hsiang Wang. She is also very grateful to the three anonymous reviewers for critique and suggestions, which improved the paper a lot. The remaining inadequacies are those of the author. This work was supported by the grant MOST108-2410-H-194019-MY3 from the Ministry of Science and Technology, Taiwan.

\section{References}

Abrusán, Márta. 2014. Weak island semantics. Oxford: Oxford University Press.

Adger, David \& Gillian Ramchand. 2005. Merge and move: Wh-dependencies revisited. Linguistic Inquiry 36(2). 161-193.

Alrenga, Peter. 2010. Comparisons of similarity and difference. In Patricia Cabredo Hofherr \& Ora Matusansky (eds.), Adjectives: Formal analyses in syntax and semantics, 155-186. Amsterdam \& Philadelphia: John Benjamins.

Anderson, Curt \& Marcin Morzycki. 2015. Degrees as kinds. Natural Language \& Linguistic Theory 33(3). 791-828. 
Bale, Alan Clinton. 2008. A universal scale of comparison. Linguistics and Philosophy 31(1). 1-55.

Beck, Sigrid. 2006. Intervention effects follow from focus interpretation. Natural Language Semantics 14(1). 1-56.

Beck, Sigrid. 2011. Comparison constructions. In Klasus von Heusinger \& Paul Porter (eds.), Semantics: An international handbook of natural language meaning, 1341-1390. Berlin: De Gruyter.

Beck, Sigrid, Toshiko Oda \& Koji Sugisaki. 2004. Parametric variation in the semantics of comparison: Japanese vs. English. Journal of East Asian Linguistics 13(4). 289-344.

Bhatt, Rajesh \& Shoichi Takahashi. 2011. Reduced and unreduced phrasal comparatives. Natural Language and Linguistic Theory 29(3). 581-620.

Bierwisch, Manfred. 1989. The semantics of gradation. In Manfred Bierwisch \& Ewald Lang (eds.), Dimensional adjectives, 71-262. Berlin: Springer.

Bošković, Željko \& Steven Franks. 2000. Across-the-board movement and LF. Syntax 3(2). 107-128.

Bresnan, Joan W. 1973. Syntax of comparative clause construction in English. Linguistic Inquiry 4(3). 275-344.

Bruening, Benjamin \& Thuan Tran. 2006. Wh-conditionals in Vietnamese and Chinese: Against unselective binding. In Proceedings of the 32nd Annual Meeting of the Berkeley Linguistics Society. 1-12.

Chao, Yuan Ren. 1968. A grammar of spoken Chinese. Berkeley, CA: University of California Press.

Chen, Sherry Yong. 2019. Deriving Wh-correlatives in Mandarin Chinese: Whmovement and (island) identity. Unpublished manuscript, Massachusetts Institute of Technology.

Chen, Shun-Ting. 2015. Ruguo shei tiaojianju de zhaoying he yanjiu [An investigation of the anaphoric relation of 'if...who...' constructions], Yuwen Xuekan [Journal of language and literature studies] 12. 10-11, 56.

Cheng, Lisa Lai-Shen \& C-T. James Huang. 1996. Two types of donkey sentences. Natural Language Semantics 4(2). 121-163.

Cheng, Lisa Lai-Shen \& C-T. James Huang. 2020. Revisiting donkey anaphora in Mandarin Chinese: A reply to Pan and Jiang (2015). International Journal of Chinese Linguistics 7(2). 167-186.

Chierchia, Gennaro. 2000. Chinese conditionals and the theory of conditionals. Journal of East Asian Linguistics 9(1). 1-54.

Cresswell, Max J. 1976. The semantics of degree. In Barbara Hall Partee (ed.), Montague Grammar, 261-292. New York: Academic Press.

Crnič, Luka \& Danny Fox. 2019. Equatives and maximality. In Daniel Altshuler \& Jessica Rett (eds.), The semantics of plurals, focus, degrees, and times: Essays in honor of Roger Schwarzschild, 163-184. Cham: Springer.

Deal, Amy Rose \& Vera Hohaus. 2019. Vague predicates, crisp judgments. Proceedings of Sinn und Bedeutung 23(1). 347-364. 
Duffley, Patrick \& Pierre Larrivée. 2019. The use of any with factive predicates. Linguistics 57(1). 195-219.

Erlewine, Michael Yoshitaka. 2018. Clausal comparison without degree abstraction in Mandarin Chinese. Natural Language \& Linguistic Theory 36(2). 445-482.

Giannakidou, Anastasia. 1994. The semantic licensing of NPIs and the Modern Greek subjunctive. Language and Cognition 4. 55-68.

Giannakidou, Anastasia. 2011. Negative and positive polarity items. In Claudia Maienborn, Klaus von Heusinger \& Paul Porter (eds.), Semantics: An international handbook of natural language meaning, 1660-1712. Berlin: De Gruyter.

Giannakidou, Anastasia \& Suwon Yoon. 2010. No NPI licensing in comparatives. Paper presented at the Annual Meeting of the Chicago Linguistic Society 46, The University of Chicago, 8-10 April.

Gu, Yang \& Jie Guo. 2015. On the internal structure of comparative constructions. In Audrey Li, Andrew Simpson \& Wei-Tien Dylan Tsai (eds.), Chinese syntax in a cross-linguistic perspective, 334-374. New York: Oxford University Press.

Hankamer, Jorge \& Line Mikkelsen. 2021. CP complements to D. Linguistic Inquiry 52(3). 473-518.

Haspelmath, Martin. 2015. Equative constructions in world-wide perspective. In Yvonne Treis \& Martine Vanhove (eds.), Similative and equative constructions: A crosslinguistic perspective, 9-32. Amsterdam: Benjamins.

Haspelmath, Martin \& Oda Buchholz. 1998. Equative and similative constructions in the languages of Europe. In Johan van der Auwera \& Donall O Baoill (eds.), Adverbial constructions in the languages of Europe, 277-334. Berlin \& New York: Mouton de Gruyter.

Heim, Irene. 1985. Notes on comparatives and related matters. Unpublished manuscript, University of Texas, Austin.

Heim, Irene. 2001. Degree operators and scope. In Caroline Féry \& Wolfgang Sternefeld (eds.), Audiatur Vox Sapientiae: A Festschrift for Arnim von Stechow, 214-239. Berlin: Akademie Verlag.

Henkelmann, Peter. 2006. Constructions of equative comparison. Sprachtypologie und Universallenforschung 59(4). 370-398.

Hsieh, I-Ta Chris. 2020. On reciprocal degree constructions: A view from Mandarin. Language and Linguistics. To appear.

Hua, Dongfan. 2000. On wh-quantification. Hong Kong: The City University of Hong Kong dissertation.

Huang, C.-T. James. 1982. Move WH in a language without WH movement. The Linguistic Review 1(4). 369-416.

Huang, C.-T. James. 2018. More on donkey anaphors and wh-conditionals. Talk given at the National Tsing Hua University, 2 August.

Huang, Yahui. 2010. On the form and meaning of Chinese bare conditionals: Not just whatever. Austin, TX: The University of Texas at Austin dissertation.

Izvorski, Roumyana. 1996. The syntax and semantics of correlative proforms. Proceedings of North East Linguistics Society 26(1). 133-147. 
Jacobson, Pauline. 1999. Towards a variable-free semantics. Linguistics and Philosophy 22. 117-185.

Kennedy, Christopher. 1999. Projecting the adjective: The syntax and semantics of gradability and comparison. New York: Garland Publishing.

Kennedy, Christopher. 2001. Polar opposition and the ontology of degrees. Linguistics and Philosophy 24(1). 33-70.

Kennedy, Christopher. 2002. Comparative deletion and optimality in syntax. Natural Language \& Linguistic Theory 20(3). 553-621.

Kennedy, Christopher. 2009. Modes of comparison. In Malcolm Elliott, James Kirby, Osamu Sawada, Eleni Staraki \& Suwon Yoon (eds.), Chicago Linguistic Society (CLS) 43, 141-165. Chicago: Chinese Linguistic Society.

Kotek, Hadas. 2019. Composing questions. Cambridge, MA: MIT Press.

Ladusaw, William Allen. 1979. Polarity sensitivity as inherent scope relations. Austin, TX: The University of Texas at Austin dissertation.

Larson, Richard K. 1988. Scope of comparatives. Linguistics \& Philosophy 11. 1-26.

Lechner, Winfried. 2001. Reduced and phrasal comparatives. Natural Language and Linguistic Theory 19(4). 683-735.

Lehrer, Adrienne. 1985. Markedness and antonymy. Journal of Linguistics 21(2). 397-429.

Li, Yen-Hui Audrey. 1992. Indefinite Wh in Mandarin Chinese. Journal of East Asian Linguistics 1(2). 125-155.

Li, Haoze. 2019. Deriving short answers from dynamicized Hamblin sets: Arguments from Mandarin wh-conditionals. Semantics and Linguistic Theory 29. 138-158.

Li, Haoze. 2020. A dynamic semantics for wh-questions. New York: New York University dissertation.

Li, Haoze. 2021. Mandarin wh-conditionals: A dynamic question approach. Natural Language Semantics 29: 401-451.

Li, Haoze \& Jess H-K. Law. 2016. Alternatives in different dimensions: A case study of focus intervention. Linguistics and Philosophy 39(3). 201-245.

Lin, Jo-Wang. 1996. Polarity licensing and wh-phrase quantification in Chinese. Amherst, MA: University of Massachusetts Amherst dissertation.

Lin, Jo-Wang. 1998. On existential polarity WH-phrases in Chinese. Journal of East Asian Linguistics 7(3). 219-255.

Lin, Jo-Wang. 2019. Chinese comparatives: Clausal or phrasal comparison. Talk given at the International Workshop on Degrees and Grammar: An East Asian Perspective, Nanjing University, 16-17 March.

Liu, Mingming. 2018. Varieties of alternatives. Beijing: Peking University Press \& Springer.

Luo, Qiong-Peng \& Stephen Crain. 2011. Do Chinese wh-conditionals have relatives in other languages? Language and Linguistics 12(4). 753-798.

Luo, Qiong-Peng \& Yuzhen Cao. 2019. Equatives are not all equal: A correlative analysis of scalar equatives in Mandarin. Chicago Linguistic Society (CLS) 54. 283-294. 
Luo, Yu-Ting Bonnie. 2014. Degree questions in Hakka and Mandarin Chinese. Hsinchu: National Chiao Tung University MA thesis.

Lü, Shuxiang. 1999. Xiandai Hanyu babai ci [Eight hundred words in Modern Chinese], Beijing: Shangwu Yinshuguan [The commercial press].

Mendia, Jon Ander. 2020. Reference to ad hoc kinds. Linguistics and Philosophy 43(6). 589-631.

Moltmann, Friederike. 2009. Degree structure as trope structure: A trope-based analysis of positive and comparative adjectives. Linguistics and Philosophy 32(1). 51-94.

Pan, Haihua \& Yan Jiang. 2015. The bound variable hierarchy and donkey anaphora in Mandarin Chinese. International Journal of Chinese Linguistics 2(2). 159-192.

Pesetsky, David. 2000. Phrasal movement and its kin. Cambridge, MA: MIT Press.

Rett, Jessica. 2015. Antonymy in space and other strictly ordered domains. Baltic International Yearbook of Cognition, Logic and Communication 10. 1-33.

Rett, Jessica. 2020. Separate but equal: A typology of equative constructions. In Peter Hallman (ed.), Interactions of degree and quantification, 163-204. Leiden \& Boston: Brill.

Schwarzschild, Roger. 2005. Measure phrases as modifiers of adjectives. Recherches Linguistiques de Vincennes 34. 207-228.

Schwarzschild, Roger. 2008. The semantics of the comparative and other degree constructions. Language and Linguistic Compass 2(2). 308-331.

Schwarzschild, Roger \& Karina Wilkinson. 2002. Quantifiers in comparatives: A semantics of degree based on intervals. Natural Language Semantics 10(1). 1-41.

Scontras, Gregory. 2017. A new kind of degree. Linguistics and Philosophy 40(2). $165-205$.

Shimoyama, Junko. 2012. Reassessing crosslinguistic variation in clausal comparatives. Natural Language Semantics 20(1). 83-113.

Srivastav, Veneeta. 1991. The syntax and semantics of correlatives. Natural Language \& Linguistic Theory 9(4). 637-686.

Stassen, Leon. 1985. Comparison and universal grammar: An essay in universal grammar. Oxford \& New York: Basil Blackwell.

Sudo, Yasutada. 2015. Hidden nominal structures in Japanese clausal comparatives. Journal of East Asian Linguistics 24(1). 1-51.

Szabolcsi, Anna. 2006. Strong vs. weak islands. In Martin Everaert \& Henk van Riemsdijk (eds), The Blackwell companion to syntax 4, 479-531. Malden, MA: Blackwell.

Tomioka, Satoshi. 2019. Intervention effects: More questions than answers. Paper presented at the Workshop on Approaches to Wh-Intervention, National University of Singapore, 7 June.

Trotzke, Andreas \& Anastasia Giannakidou. 2019. Exclamatives as emotive assertions of intensity. lingbuzz/004838 (accessed 28 October 2021).

Vanden Wyngaerd, Guido, Michal Starke, Karen De Clercq \& Pavel Caha. 2020. How to be positive. GLOSSA - A Journal of General Linguistics 5(1). https://doi. org/10.5334/gjgl.1114 (accessed 28 October 2021). 
von Stechow, Arnim. 1984. Comparing semantic theories of comparison. Journal of Semantics 3(1-2). 1-77.

von Stechow, Arnim, Sveta Krasikova \& Doris Penka. 2005. Different approaches to the semantics of comparison. Unpublished manuscript, University of Tübingen.

Wang, Xin. 2016. "Shenme...shenme ju" de luoji yufa tezheng yu tuiyan [The logicalgrammatical features of the "shenme...shenme" sentence and its deduction]. Luojixue Yanjiu [Studies in logic] 9(1). 63-80.

Wellwood, Alexis. 2015. On the semantics of comparison across categories. Linguistics and Philosophy 38(1). 67-101.

Wilder, Chris. 1994. Coordination, ATB, and ellipsis. GAGL: Groninger Arbeiten zur germanistischen Linguistik 37. 291-329.

Xiang, Yimei. 2016. Interpreting questions with non-exhaustive answers. Cambridge, MA: Harvard University dissertation.

Xiang, Yimei. 2020. A hybrid categorial approach of question composition. Linguistics and Philosophy. Online first article.

Xie, Zhiguo. 2014. The degree use of the possessive verb yǒu in Mandarin Chinese: A unified analysis and its theoretical implications. Journal of East Asian Linguistics 23(2). 113-156.

Yang, Lan. 2019. A study on the anaphoric usage of interrogative pronouns in Modern Chinese. Shanghai: Shanghai International Studies University MA Thesis.

Zhang, Min. 2009. Hanyu huatihua jiegou xianzhi zhong de linjie tiaojian: Renzhi chuli jiaodu de lunzheng [A revisit of the subjacency constraint in Chinese topicalization from the perspective of cognitive processing]. Yuyanxue Luncong [Essays on linguistics] 39. 523-572. Beijing: Peking University Press.

Zhang, Niina Ning. 2002. Island effects and episodic eventualities in Chinese topicalization. In Daniel Hole, Paul Law \& Niina Zhang (eds.), Linguistics by heart: In honor of Horst-Dieter Gasde. ZAS-Berlin.

Zhang, Niina Ning. 2019. WH expressions and degree abstraction in equatives. Talk given at the International Workshop on Degrees and Grammar: An East Asian Perspective, Nanjing University, 16-17 March.

Zhang, Niina Ning. 2020. Correlative adverbs in Mandarin. Paper presented at the 13th Workshop on Formal Syntax and Semantics (FOSS 13), Academia Sinica, 16-17 October.

\section{Niina Ning Zhang}

Mailing address: Graduate Institute of Linguistics, National Chung Cheng University, 168 University Rd., Min-Hsiung, Chia-Yi 62102 Taiwan

Email:

Received: Ingnz@ccu.edu.tw

Accepted: September 1, 2020 July 22, 2021 


\title{
華語表程度的雙句句式
}

\author{
張寧 \\ 中正大學
}

\section{提要}

如果兩個 “多 (麼)” 句連在一起, “多（麼）” 這個詞就不再有疑問語意。這樣 的雙程度句式實際上是等比句式, 類似於英語的 as... as 等比句式。所不同的是在這 樣的華語句式中, 第一個 “多 (麼) ” 句表達比較的標準, 但在英語的雙 as 句中, 則是第二個 as 句表達比較的標準。要生成這樣的程度比較句, 需要一個比較量化詞, 也需要把兩個句子都分別進行謂語化（即謂詞抽象）。句式中的兩個 “多（麼）” 詞組都是變量。這項研究揭示出華語確實有量化的程度比較句式, 而且該句式的兩 個句子都含有非疑問用法的 WH 形式。

\section{關鍵詞}

雙程度變量句式, 疑問詞, 程度, 等比句式, 謂詞抽象 
